\title{
Automated Image Analysis Comparing EDTA and Maleic Acid in Smear Layer Removal from Instrumented Human Posterior Root Canals
}

\author{
Lauren P. Namsupak
}

West Virginia University

Follow this and additional works at: https://researchrepository.wvu.edu/etd

\section{Recommended Citation}

Namsupak, Lauren P., "Automated Image Analysis Comparing EDTA and Maleic Acid in Smear Layer Removal from Instrumented Human Posterior Root Canals" (2011). Graduate Theses, Dissertations, and Problem Reports. 3321.

https://researchrepository.wvu.edu/etd/3321

This Thesis is protected by copyright and/or related rights. It has been brought to you by the The Research Repository @ WVU with permission from the rights-holder(s). You are free to use this Thesis in any way that is permitted by the copyright and related rights legislation that applies to your use. For other uses you must obtain permission from the rights-holder(s) directly, unless additional rights are indicated by a Creative Commons license in the record and/ or on the work itself. This Thesis has been accepted for inclusion in WVU Graduate Theses, Dissertations, and Problem Reports collection by an authorized administrator of The Research Repository @ WVU. For more information, please contact researchrepository@mail.wvu.edu. 
Automated Image Analysis Comparing EDTA and Maleic Acid in Smear Layer Removal from Instrumented Human Posterior Root Canals

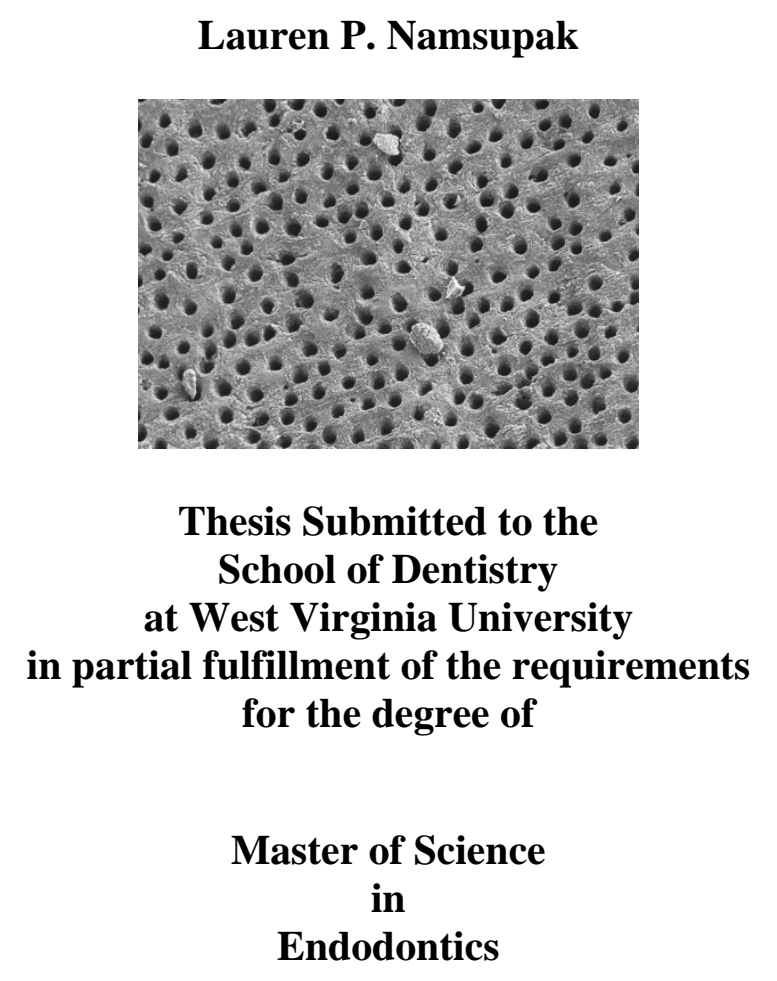

\author{
John Thomas, MS, PhD, Chair \\ C. Russell Jackson, DDS, MS \\ Thomas Razmus, DDS, MS
}

Department of Endodontics

Morgantown, WV

2011

Keywords:

Maleic Acid, EDTA, Smear Layer, Automated Image Analysis, Irrigation, Root Canal, Endodontics 


\begin{abstract}
Automated Image Analysis Comparing EDTA and Maleic Acid in Smear Layer Removal from Instrumented Human Posterior Root Canals
\end{abstract}

Lauren P. Namsupak

EDTA has long been the gold standard for smear layer removal in endodontics. Recently Ballal has suggested maleic acid as a more effective alternative to EDTA, but more research is needed before it can be used in clinical practice. This study focused on comparing EDTA to maleic acid when removing the smear layer from curved root canals in human posterior teeth. Fifty-one posterior teeth were randomly selected and assigned to three groups: 17\% EDTA, 7\% maleic acid, and a $0.9 \%$ saline control. The teeth were prepared using K-files to an ISO size $40 \mathrm{MAF}$, step-backed to an ISO size 60 and irrigated with $\mathrm{NaOCl}$ between each file size. A final irrigation was performed with $5 \mathrm{~mL}$ of the respective group solution over 1 minute. The teeth were then dried and stored in a humidor until time for sectioning. The teeth were dehydrated, mounted and gold-palladium sputtered. Photomicrographs were taken using a SEM at 1,000 x, then 144 images were analyzed by digital image software to assess the surface area in pixels ${ }^{2}$ of open dentin tubules. The data was analyzed with a repeated measure ANOVA. It was found that the maleic acid produced greater surface area of open tubules than EDTA at the three defined canal regions ( A. Coronal, B. Middle, C. Apical) but the difference was only significant in section B of the canal, where respectively, maleic acid was 120,433 pixels ${ }^{2}$ compared to EDTA with 66,399 pixels $^{2}$. Maleic acid needs to be seriously considered as an alternative to EDTA. 


\section{TABLE OF CONTENTS}

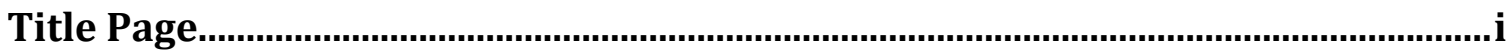

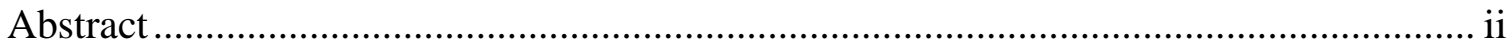

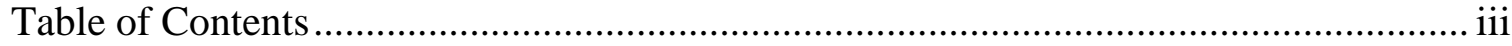

List of Tables ...................................................................................................... iv

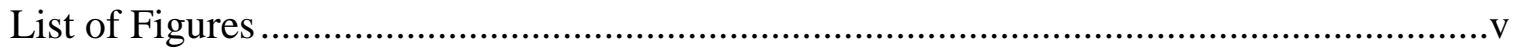

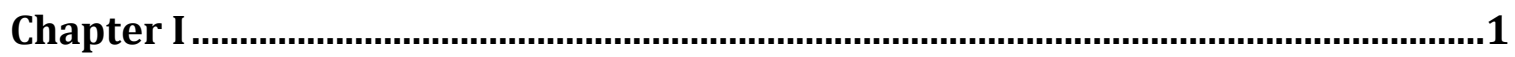

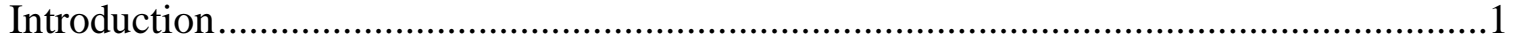

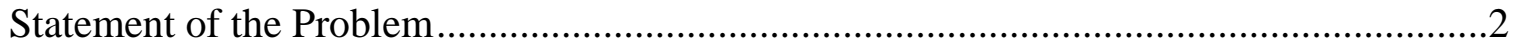

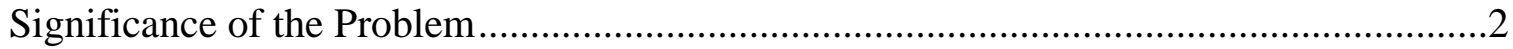

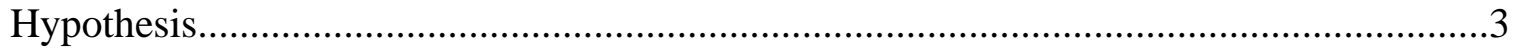

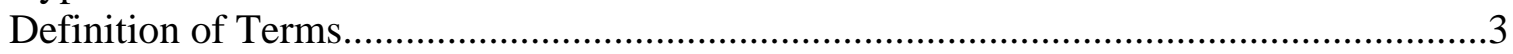

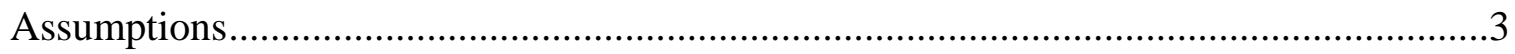

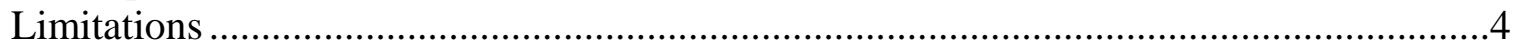

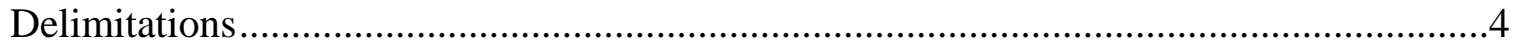

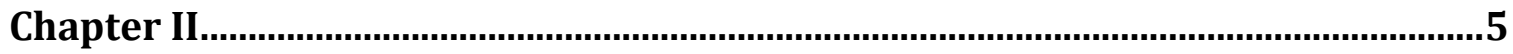

Literature Review..............................................................................................

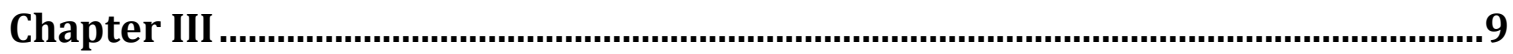

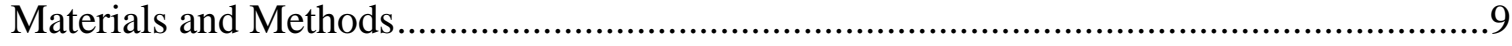

Chapter IV

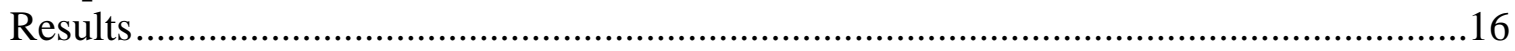

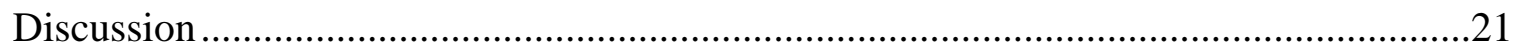

Chapter V

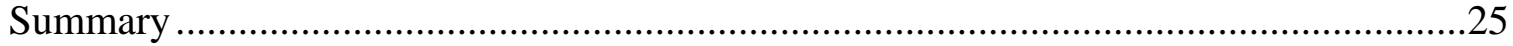

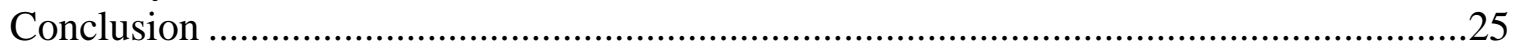

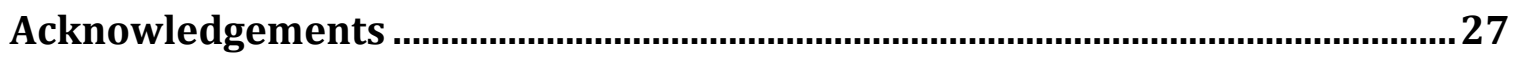

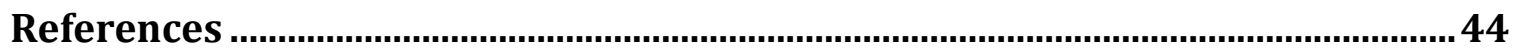

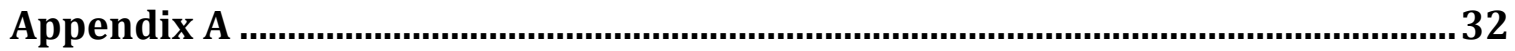

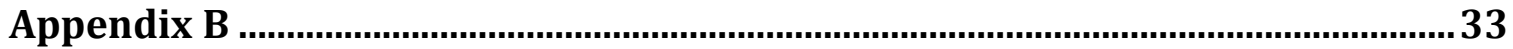




\section{LIST OF TABLES}

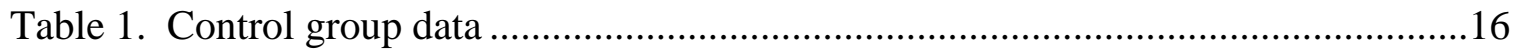

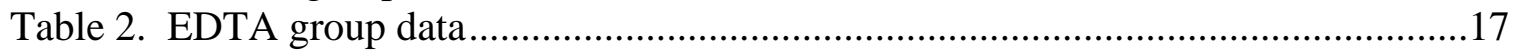

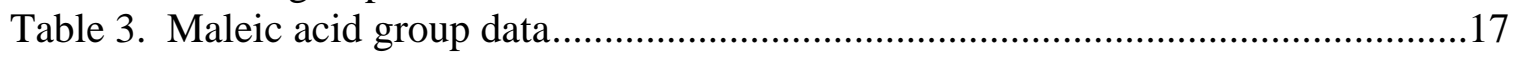

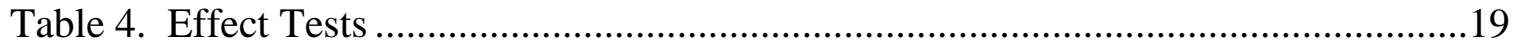

Table 5. Group - Least Squares Means ....................................................................19

Table 6. Canal Location - Least Squares Means..........................................................20

Table 7. Irrigant*Canal Location - Least Squares Means............................................20 


\section{LIST OF FIGURES}

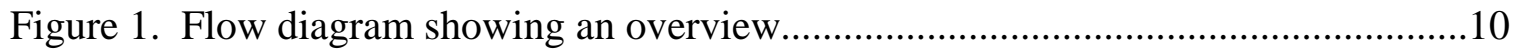

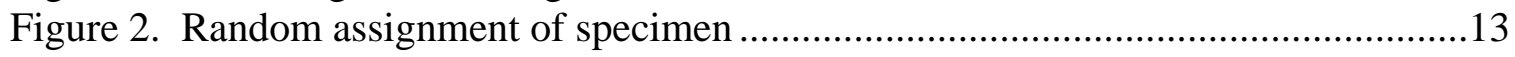

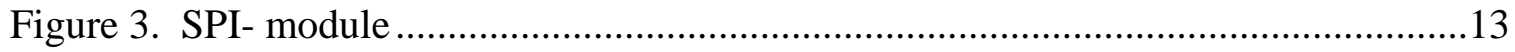

Figure 4. Hitachi S-4700 Field Emission Scanning Electron Microscope .......................14

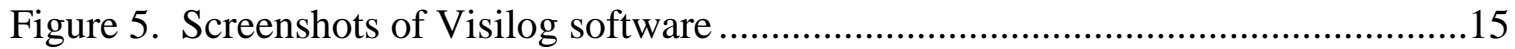

Figure 6. SEM Images of Tooth number 15 in the Control Group.................................18

Figure 7. SEM Images of Tooth number 6 in the EDTA Group ....................................18

Figure 8. SEM Images of Tooth number 5 in the Maleic Acid Group ............................19

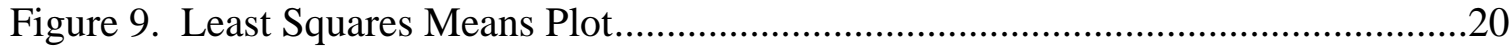




\section{CHAPTER I}

\section{INTRODUCTION}

Since the description of the smear layer by McComb and Smith in 1975 many endodontists have attempted to remove it during the irrigation process (1). Pashley said the smear layer was similar to wood being covered by wet sawdust (2). It has been demonstrated that the smear layer can harbor bacteria and prevent a proper seal of the root canal during obturation. It has been demonstrated by multiple researchers that the smear layer negatively affects the seal created during obturation. Sodium hypochlorite is considered the gold standard of irrigation solutions because it dissolves organic tissues. However, it cannot remove the smear layer or reach the organic materials hidden under the smear layer. Some have also tried to use lasers and ultrasonic devices, but the most common method of removing the smear layer is a final rinse with EDTA.

There have been many papers about the use of EDTA to remove the smear layer. EDTA is a chelating agent and was first introduced into endodontics by Nygaard-Ostby in 1957 to prepare narrow and calcified root canals (3). EDTA has been shown to cause dentinal erosion $(4,5,6)$. It is also undetermined the length of time EDTA requires to be effective (3). Some papers report that it takes as long as 15 minutes for EDTA to be effective. If that is true then the common practitioner cannot afford to wait while administering a final rinse.

Recently maleic acid (MA) has been suggested as an alternative to EDTA. Ballal has done the bulk of this research and shown that maleic is more effective at removing the smear layer in the apical third, is less toxic, and improves the apical seal when compared to EDTA $(7,8,9)$. However, Ballal and others researching MA have only used anterior straight-rooted teeth. There is also very little research that has been done on MA as a smear layer removal 
agent. It is important that more research be done on MA so that it can be utilized clinically. Although MA has been demonstrated to be effective in straight roots, it has not been tested in curved roots or the smaller canals of posterior teeth. The smear layer is also typically evaluated by observers rating the photomicrographs, which is subjective and not a true quantitative result. Through automated image analysis it is now possible to assess smear layer removal utilizing computers and have a true value of open dentin tubule area $(10,11)$. Using the methods outlined by Ballal and George $(7,10)$, this author will attempt to demonstrate the effectiveness of maleic acid in removing the smear layer from curved human root canals in posterior teeth.

\section{STATEMENT OF THE PROBLEM}

Is there a difference in the efficacy of smear layer removal in the instrumented root canal of a human molar, with curved roots, between maleic acid (MA) and ethylenediaminetetraacetic acid (EDTA)?

\section{SIGNIFICANCE OF THE PROBLEM}

Although it has been demonstrated that EDTA is effective in removing the smear layer, the current protocol for EDTA has not been established. Some papers report that it takes as long as 15 minutes for EDTA to be effective, while other papers show only one minute is necessary. There are also papers that demonstrate any exposure to EDTA over one minute is corrosive to the dentin tubules. Several papers have demonstrated that EDTA does not remove the smear layer in the apical third of the tooth; therefore it is not effective in the whole canal.

Recent studies have shown that maleic acid (MA) could be a more effective alternative to EDTA. It has been demonstrated that MA removes the smear layer in one minute and reaches the apical third of the tooth. However, the research is still fairly new and has only been 
conducted on single rooted, straight teeth. It needs to be demonstrated that MA is effective in multi-rooted teeth with curved canals. If MA is effective in curved canals, then it would be more practical for practitioners to use an irrigant that removes the smear layer throughout the whole canal and is not corrosive to dentin tubules.

\section{HYPOTHESIS}

There is no significant difference between using maleic acid or EDTA to remove the smear layer.

\section{DEFINITION OF TERMS}

Biofilm- aggregation of microorganisms in an extracellular polysaccharide matrix associated with a surface

Chelating Agent-causes decalcification of dentin by forming stable complexes with calcium Obturation- the process in which the root canal is filled

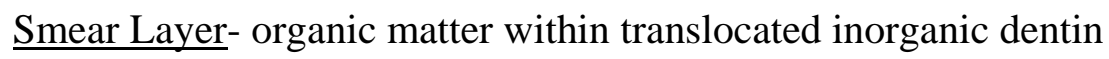

\section{ASSUMPTIONS}

(1) Practitioners want to remove smear layer. (2) Practitioners do not want to rinse with EDTA due to the time required. (3) Maleic Acid is easily accessible by practitioners. (4) Maleic acid is safe to use in smear layer removal. (5) Maleic acid requires less time than EDTA to remove the smear layer. 


\section{LIMITATIONS}

(1) Irrigation is being done by a human and there may be an inconsistent flow. (2) The teeth are being prepared by a human so human error is again introduced. (3) An In vitro experiment is simulating an In vivo situation.

\section{DELIMINATIONS}

(1) Computer software is calculating the area of smear layer removal. (2) The same volume of solutions will be administered. (3) New bottles of each product will be used that have been tested at the factory for quality control. (4) All teeth will be from the posterior and will have a curved root of 10 or more. (5) All teeth will be processed in the same manner and under the same conditions. 


\section{CHAPTER II}

\section{REVIEW OF LITERATURE}

In 1975 McComb and Smith first described the smear layer of root canals; stating that it consisted of dentin, the remnants of odontoblastic processes, pulp tissue, and bacteria (1). The smear layer was first researched in relation to restorative dentistry, but it is also important to endodontics because if the bacteria laden smear layer remains in the root canal it could provide a reservoir of potential irritants (2). Violich and Chandler state the smear layer should be removed for the following reasons: the unpredictable thickness and volume, it contains bacteria and their by-products, it may limit the optimum penetration of disinfecting agents, it can act as a barrier between filling materials and the canal wall which compromises the formation of a good seal, and the loosely adherent structure has potential for leakage and bacterial passage between filling and the dentinal walls (1).

The main area of interest pertaining to the smear layer is how it affects sealing ability. The most common way to assess sealing ability is to measure coronal or apical leakage using Indian ink. There have been a multitude of studies performed to measure the seal with and without the smear layer. Saunders et al. and Taylor et al. both conducted studies that found removal of the smear layer reduced coronal leakage $(12,13)$. Froes et al. assessed four different obturation techniques and found that the lateral condensation with an accessory main cone group and the thermoplasticized groups leaked less with the smear layer present, but the lateral condensation with a standardized main cone leaked more with the smear layer present (14). Timpawat et al. found that removal of the smear layer caused more apical leakage when using the warm vertical technique (15). In a separate study it was found that the smear layer made no difference when using Thermafil (16). Several other studies concluded that removing the smear 
layer produced less apical and coronal leakage $(17,18,19)$. Tzanetakis et al. reported that removal of the smear layer increased the ability of filling materials to prevent fluid movement when using warm obturation techniques but makes no difference when using the cold lateral technique (20). There are many studies and they may seem contradictory to each other depending on the articles chosen. Shahravan et al. performed a review and meta-analysis that stated smear layer removal improves the fluid-tight seal of the root canal system; while other factors, such as obturation technique or the sealer, have no significant effects (21).

Bacterial penetration is another area of importance when evaluating whether or not the smear layer should be removed. Removal of the smear layer has been shown to decrease the bacterial leakage through the root canal (22). Bacterial penetration was shown to significantly decrease in the presence of RealSeal and AH Plus sealers when the smear layer was removed (23). When the smear layer is removed sealer can get into the dentin tubules, but this is not possible with the smear layer present (24). Although there are a few publications demonstrating that the removal of the smear layer makes no difference, the vast majority report that removal of the smear layer is imperative.

In order to analyze smear layer removal the root canals must be viewed with a scanning electron microscope. The most common method of reviewing the data involves blinded evaluators scoring the photomicrographs by using qualitative or semiquantitative scales. These methods are too subjective and can introduce experimental error. As technology has advanced there has been experimentation with quantitative analysis of dentinal tubules. Ciocca et al. outlined a procedure to use automated analysis to calculate the total tubule surface area which should help eliminate human error (11). It has also been demonstrated that automated image analysis is a helpful method in evaluating the smear layer removal (10). However, automated 
image analysis has not been utilized until now to process data in a smear layer experiment. The methodology from these two papers will be the basis for the data analysis in this paper.

Irrigation is the process of removing the debris formed during mechanical preparation and delivering an antimicrobial substance into the canal. In order to deliver the irrigant into the canal it has been determined that an ISO size no. 30 file is the minimum instrumentation needed (25). The most common irrigant used is sodium hypochlorite, but this does not remove the smear layer. Sodium hypochlorite is excellent at removing organic debris and can dissolve necrotic tissue. Because the smear layer needs to be removed, it is recommended that the final irrigation consist of rinsing with 5-10 $\mathrm{mL}$ of a chelator for one minute and then a final rinse with sodium hypochlorite (26). This final rinse allows the bacteria that were underneath the smear layer to be removed.

A prime example of a chelator is ethylenediaminetetraacetic acid (EDTA). NygaardOstby introduced chelators into endodontics in 1957 to aid in the preparation of narrow and calcified root canals (3). The exposure time that EDTA requires to remove the smear layer has long been argued. In 2002 it was shown that exposure time of one minute removes the smear layer while ten minutes causes excessive dentinal erosion (4). As little as 1\% EDTA removes the smear layer, but exposure of just one minute causes restricted erosion (5). It is important to note that EDTA negatively intereferes with sodium hypochlorite by causing a loss of available chlorine and decreasing its antimicrobial ability (27). The apical region is very important to ensure a proper seal, but EDTA is not completely effective in the apical third of the canal (28). EDTA requires more than one minute in the apical third to completely remove the smear layer (29), but this would increase the erosion of dentin. The recommended final irrigation of EDTA then sodium hypochlorite has been shown to accelerate dentinal erosion $(6,30)$, while filling the 
canals with EDTA while filing with nickel-titanium hand files increases the deviation of curved roots (31). There is a need for a better smear layer removal agent.

Recent studies have shown that maleic acid may be the final irrigant endodontics has been looking for. In 2002 it was demonstrated that maleic acid removed dentin as an etching agent and opened the tubule orifices (32). In 2003 different concentrations of maleic acid were tested in removal of the endodontic smear layer (33). That study showed that the maleic acid removed the smear layer significantly better than EDTA and 5\% and 7\% maleic acid showed no significant difference in the ability to remove the smear layer effectively. Ballal is the predominant investigator of maleic acid and its possible replacement of EDTA. He found that $7 \%$ maleic acid is more efficient than 17\% EDTA in removing the smear layer from the apical third of the root canal system (7). Using Chinese hamster fibroblasts cells it was demonstrated that 7\% maleic acid is less toxic than 17\% EDTA (8). Ballal has also demonstrated that final irrigation with maleic acid improves the apical seal when using AH Plus (9). The problem is that all these studies were conducted on anterior straight-rooted teeth. Therefore, maleic acid may only be clinically relevant for such teeth. If maleic acid is also effective in teeth with curved roots, then it could be a viable option for replacing EDTA. The author of this paper believes that maleic acid needs to be tested in curved roots and that automated image analysis will make the results stronger. Using methodology outlined by Ballal this in vitro study will be completed on posterior teeth with curved roots to demonstrate the ability of maleic acid to remove the smear layer(7). 


\section{CHAPTER III}

\section{MATERIALS \& METHODS}

The following overview is represented in the Figure 1 flow chart. The selection process began with fifty-one human posterior teeth with curved roots. Each tooth was prepared in an identical fashion using a step back technique. Then the teeth were randomly selected to three equal sized treatment groups: saline (control), EDTA, and maleic acid. After final irrigation was performed each group was taken to the SEM for imaging. The saved image files underwent an automated image analysis using the Visilog software. All data was recorded and then statistical analysis was performed. 
Figure 1. Flow diagram showing an overview of this research project.

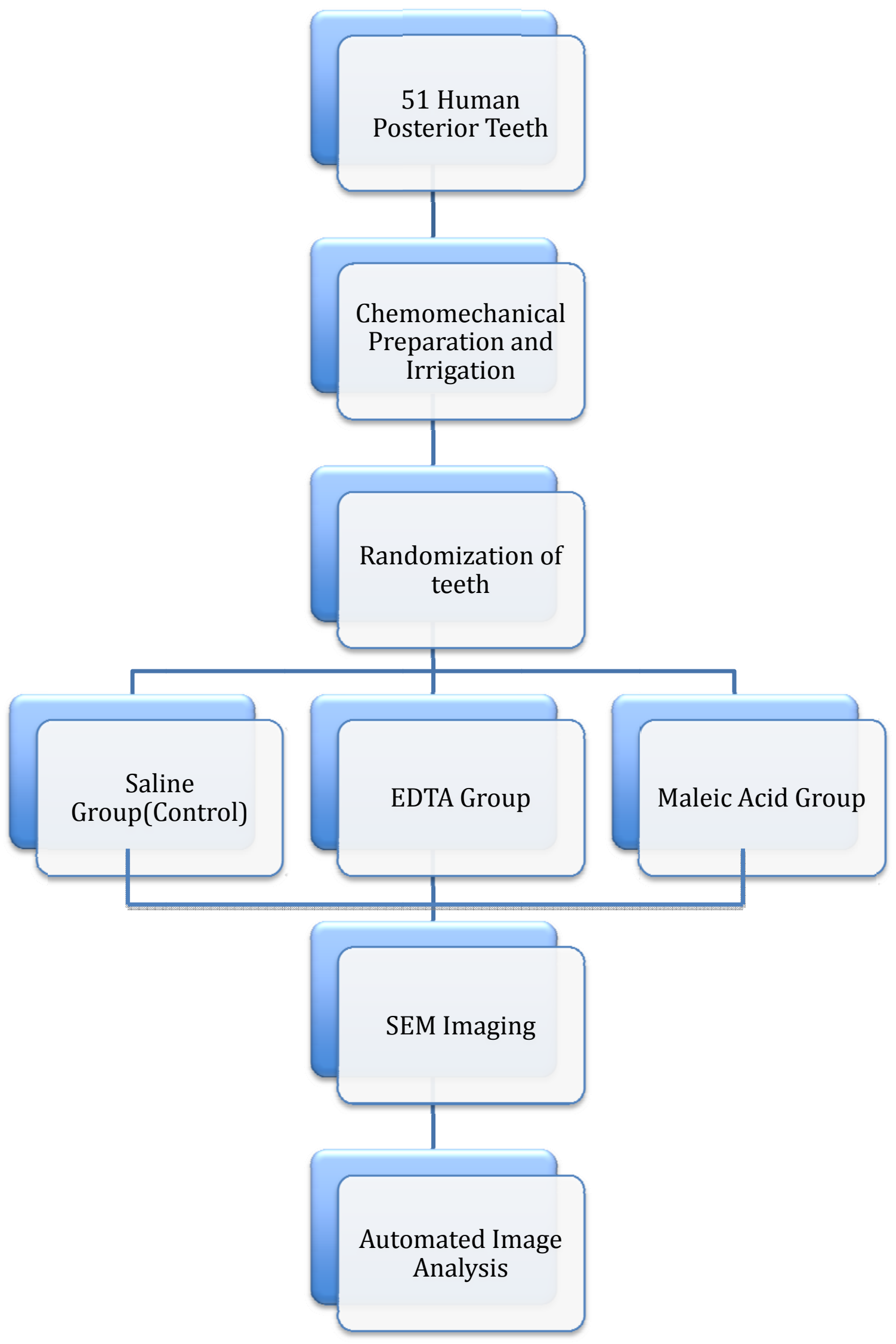


Fifty-one extracted human posterior teeth with curved roots were selected. All teeth had mature apices. A brush was used to remove all superficial tissue and the teeth were stored in saline at room temperature. Crowns of the teeth were removed to create a standard root length of $15 \mathrm{~mm}$. A no. $10 \mathrm{~K}$ file was inserted into each canal until it was just visible at the apical foramen and $1 \mathrm{~mm}$ was subtracted from that point to establish a working length.

Chemomechanical preparation was performed with a step-back technique using K files (Dentsply Maillefer, Johnson City, TN). The canals were enlarged to an ISO size no. 40 and step backed to ISO size no. 60 file. Gates Glidden drills (Dentsply Maillefer, Johnson City, TN) no. 2-4 were used to enlarge the coronal third of the root canal. Irrigation was performed with $1 \mathrm{~mL}$ of $2.5 \%$ of $\mathrm{NaOCl}$ solution after each file change.

Teeth were then randomly assigned to one of three groups: (1) 17 teeth using EDTA, (2) 17 teeth using Maleic Acid, and (3) 17 teeth using saline (Figure 2). Final irrigation was performed as follows: (1) EDTA group: $5 \mathrm{~mL}$ of 17\% EDTA (Henry Schein, Melville, NY) for 1 minute followed by $5 \mathrm{~mL}$ of $2.5 \% \mathrm{NaOCl}$ for 1 minute, (2) maleic acid group: $5 \mathrm{~mL}$ of $7 \%$ maleic acid (Medical Center Pharmacy, Morgantown, WV) for 1 minute followed by $5 \mathrm{~mL}$ of 2.5\% NaOCl for 1 minute, and (3) control group: $5 \mathrm{~mL}$ of $0.9 \%$ saline (Kimberly-Clark Healthcare, Roswell, GA)for 1 minute. All the irrigating solutions were introduced into the canals using a stainless steel 30-G safe sided needle (Dentsply Tulsa Dental, Johnson City, TN). The needle was placed within 1 to $2 \mathrm{~mm}$ of the working length in each canal. In order to remove any precipitates that may have formed during irrigation, the canals were then irrigated with $5 \mathrm{~mL}$ of distilled water. The canals were then dried using sterile paper points and stored in a humidor.

The teeth were then prepared for the scanning electron microscope (SEM) by using a diamond disc to place a longitudinal groove on the buccal and lingual surfaces of each root 
without penetrating the canal. Using a chisel, the roots were split into two halves and then stored in deionized water until time for analysis. The specimen were dehydrated with $100 \%$ ethyl alcohol (Fisher Scientific, Hampton, $\mathrm{NH}$ ) and placed in a furnace at $60 \mathrm{C}$ for 24 hours. The samples were then mounted on metallic stubs, gold-palladium sputtered using an ion sputter, and examined under SEM for smear layer presence (Figures 3 and 4). Photomicrographs were taken to observe the surface morphology at X 1,000 magnification of canal walls at the coronal (10-12 $\mathrm{mm}$ from apex), middle (6-7 $\mathrm{mm}$ from apex), and apical (1-2 $\mathrm{mm}$ from apex) thirds of each specimen. The SEM process is described in greater detail in appendix A and all captured images are located in appendix B. These images were evaluated by Visilog 6.3 software. Following similar methods outlined by George et al. the area of open dentinal tubules were configured and calculated through automated image analysis (10). The original image was uploaded to the program (Figure 5A). Using a threshold of 0-50 on the grayscale the images went through binarisation (Figure 5B). Images were then eroded to delete extraneous information and dilated to bring it back to its true size (Figures 5C and 5D). The program then analyzed the image by outlining the dentin tubule and calculating its surface area in pixels ${ }^{2}$. Once the surface area was calculated for each tubule they were added together to determine the total surface area of open dentin tubules (Figures 5E and 5F). A repeated measures analysis of variance (ANOVA) was used to determine if there was a significant difference between irrigants with a confidence level of $\mathrm{p}<0.01$. 
Figure 2. Random assignment of specimen to the following groups EDTA (Henry Schein, Melville, NY), Maleic Acid (Medical Center Pharmacy, Morgantown, WV), and control. Specimen were randomly assigned using a random number generator and placed into individual specimen containers.

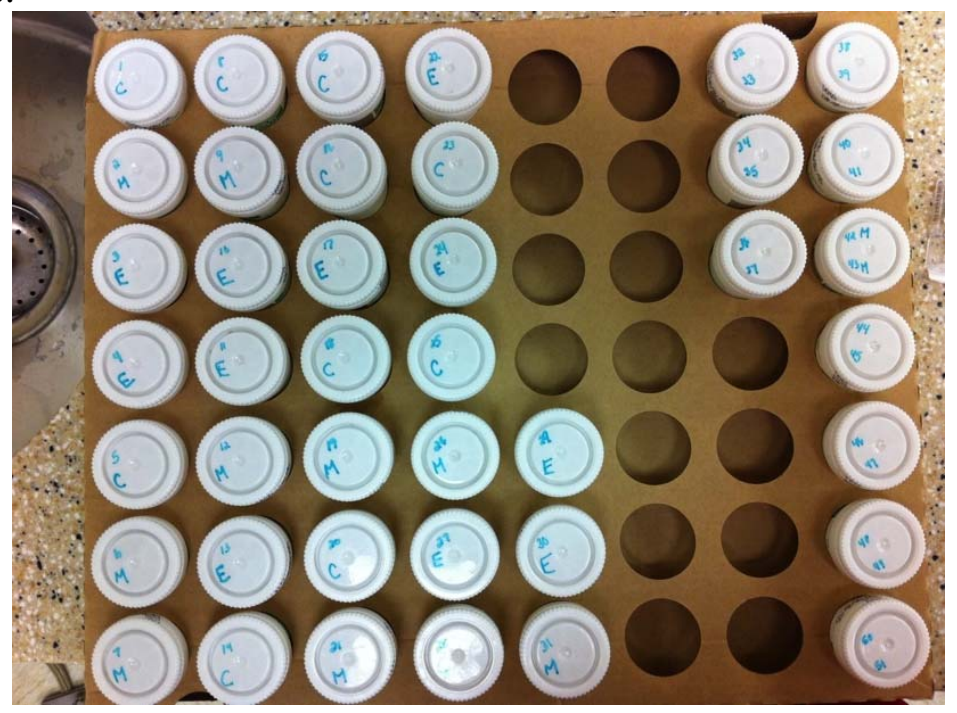

Figure 3. SPI- module Sputter Coater used to coat specimen with Gold-palladium.

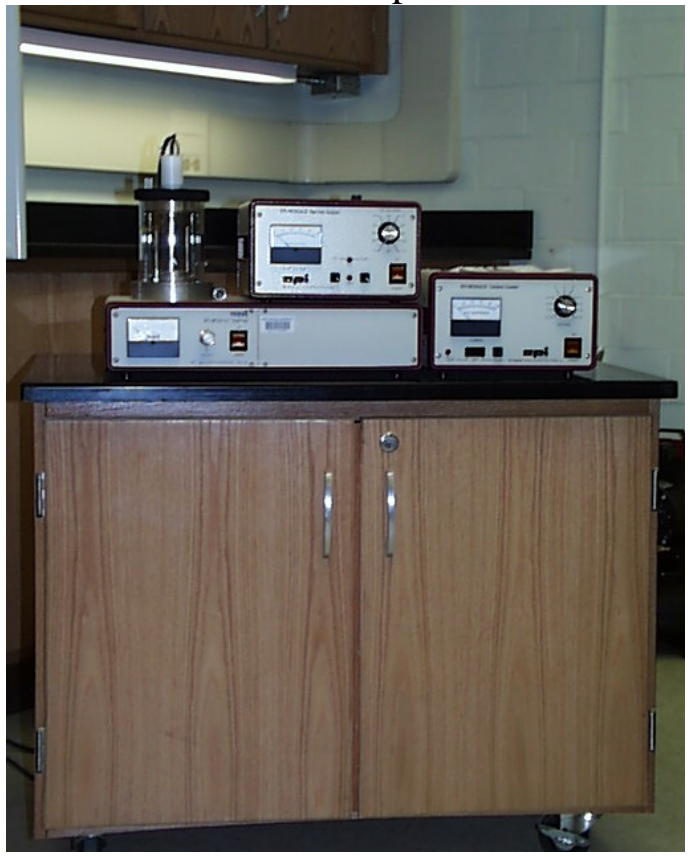


Figure 4. Hitachi S-4700 Field Emission Scanning Electron Microscope. Specimens were examined at X 1,000 magnification.

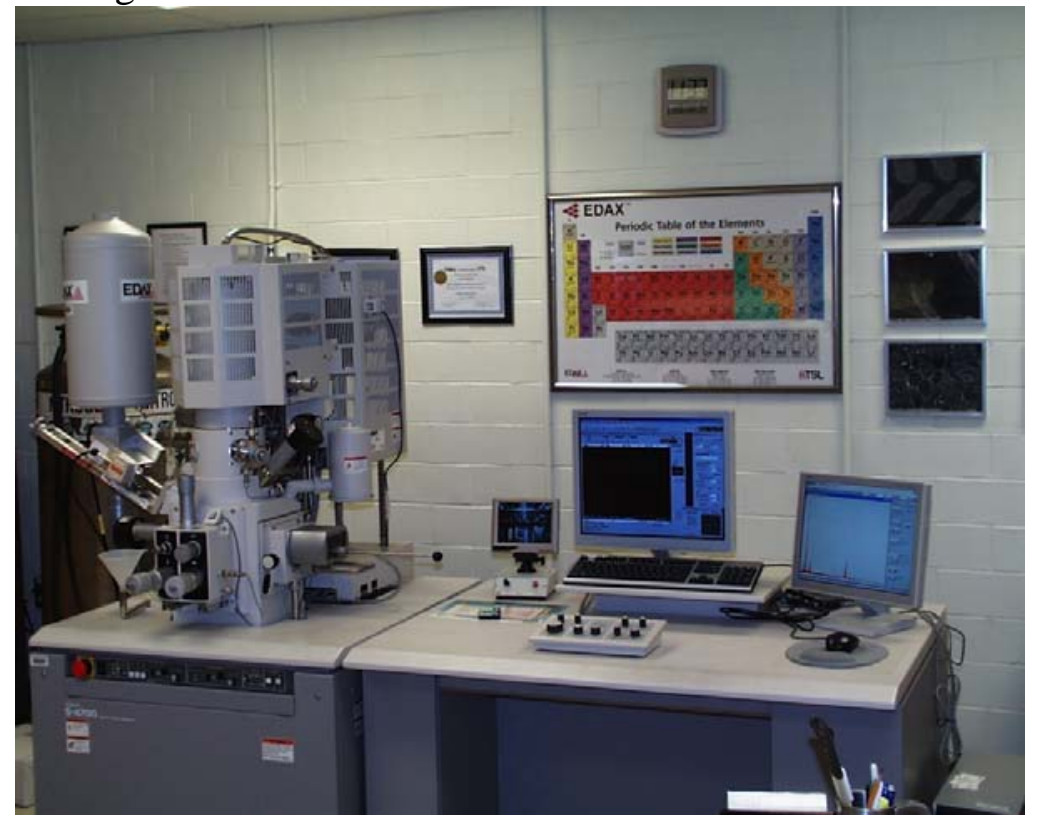



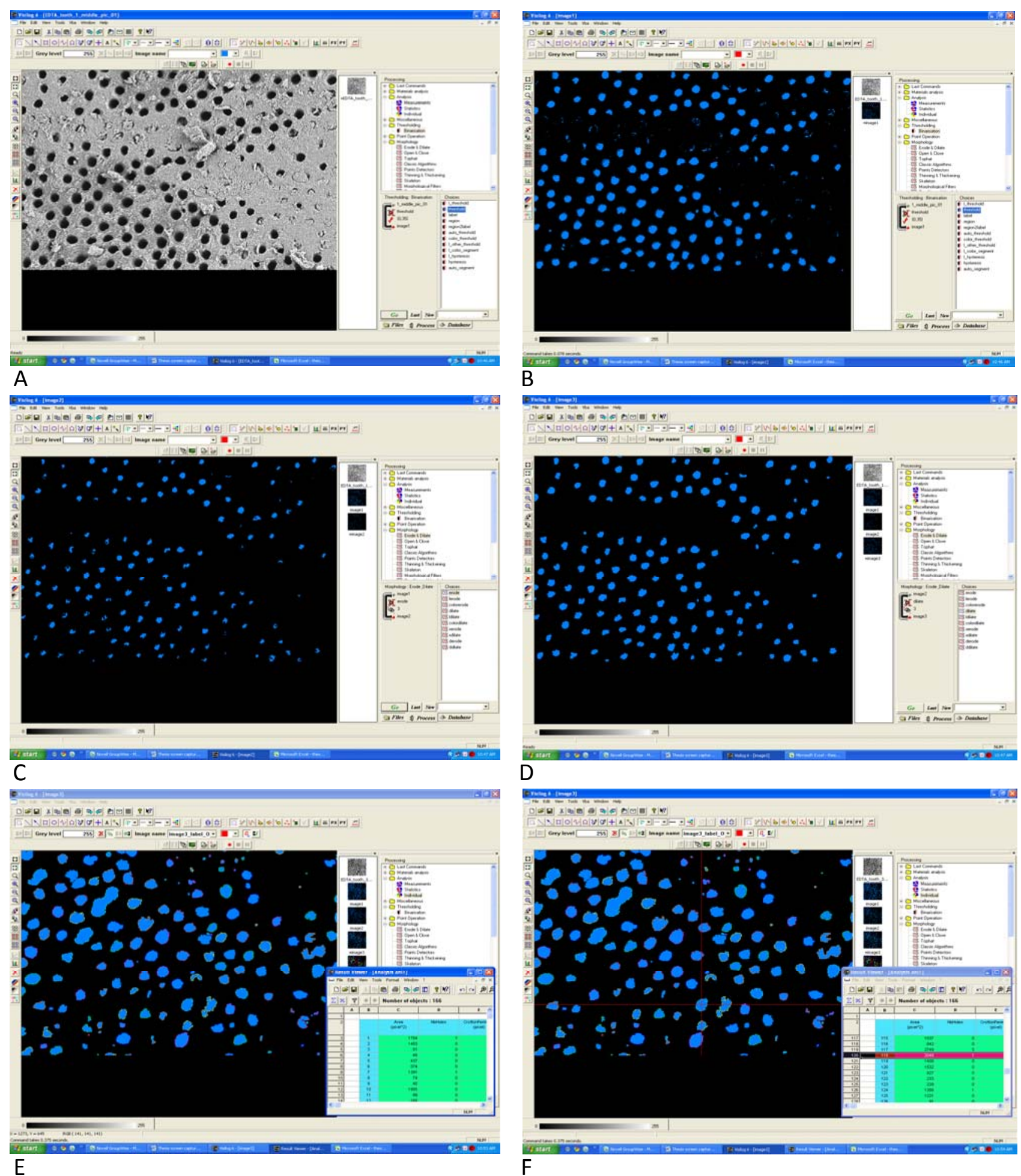

F $\mathrm{F}$

Figure 5. Screenshots of Visilog software used for image analysis. The grayscale threshold of 0-50 was used to determine open dentin tubules. The program then shaded the areas of interest blue while converting the dentinal regions black. (A) Original image uploaded for analysis (B) Binarization of original image. (C) Image eroded to get rid of extraneous material. (D) Image dilated to restore tubule size. (E) Image analysis of each tubule surface area. (F) Individual dentin tubule selected during image analysis. 


\section{CHAPTER IV}

\section{RESULTS}

Tables 1, 2, and 3 display the data collected from image analysis. The MA group is the only one to always have open tubules. The EDTA and MA groups always had the greatest surface area of open tubules in the coronal portion, followed by the middle and then the apex. On visiual inspection of the images there was a heavy smear layer present in the saline group at all levels (Figure 6). There was some peritubular dentinal erosion observed in the EDTA group but not in the other groups (Figures 7 and 8).

A repeated measures ANOVA statistical analysis (Tables 4-7) reveals that the there was a difference when comparing the control to the other groups. Both MA and EDTA were significantly better than saline at removing smear layer at all levels of the canal. There was no difference in MA and EDTA at the coronal or apical levels but MA was significantly better than EDTA at the middle level in removing smear layer.

Table 1. Control group data.

\begin{tabular}{lccc}
\hline Tooth \# & Crown & Middle & Apex \\
\hline 1 & 0 & 93 & 11344 \\
2 & 3795 & 32057 & 0 \\
3 & 408 & 1693 & 113 \\
4 & 5103 & 34214 & 509 \\
5 & 1335 & 10071 & 404 \\
6 & 678 & 51016 & 454 \\
7 & 6689 & 0 & 0 \\
8 & 0 & 594 & 0 \\
9 & 59760 & 0 & 0 \\
10 & 3010 & 10634 & 0 \\
11 & 0 & 0 & 0 \\
12 & 5584 & 0 & 0 \\
13 & 0 & 7744 & 1740 \\
14 & 413 & 0 & 0 \\
15 & 1112 & 508 & 540 \\
\hline Average & 5859 & 9908 & 1007 \\
Range & $0-59760$ & $0-51016$ & $0-11344$ \\
\hline
\end{tabular}


Table 2. EDTA group data.

\begin{tabular}{lccc}
\hline Tooth \# & Crown & Middle & Apex \\
\hline 1 & 50486 & 62092 & 46019 \\
2 & 152508 & 92607 & 43316 \\
3 & 188455 & 125850 & 146393 \\
4 & 79325 & 79697 & 61055 \\
5 & 69290 & 24169 & 799 \\
6 & 151020 & 94858 & 412 \\
7 & 84464 & 26236 & 16327 \\
8 & 70975 & 37028 & 39710 \\
9 & 202299 & 232218 & 150319 \\
10 & invalid & invalid & 21710 \\
11 & 18546 & 75052 & 18198 \\
12 & 145639 & 2250 & 0 \\
13 & 77749 & 13104 & 9366 \\
14 & 0 & 246 & 1511 \\
15 & 263064 & 77505 & 7048 \\
16 & 154931 & 44894 & 0 \\
17 & 235020 & 74571 & invalid \\
\hline Average & 121486 & 66399 & 35136 \\
Range & $0-235020$ & $246-232218$ & $0-150319$ \\
\hline
\end{tabular}

Table 3. Maleic acid group data.

\begin{tabular}{lccc}
\hline tooth \# & Crown & Middle & Apex \\
\hline 1 & 1629 & 43958 & 35013 \\
2 & 152044 & 76375 & 14533 \\
3 & 189721 & 94509 & 114551 \\
4 & 96182 & 123687 & 71820 \\
5 & 37513 & 183644 & 77400 \\
6 & 65857 & 51340 & 37413 \\
7 & 168123 & 128602 & 17861 \\
8 & 50189 & 9119 & 4476 \\
9 & 29293 & 28454 & 156822 \\
10 & 253514 & 340223 & 23824 \\
11 & 241854 & 182737 & 45452 \\
12 & 178651 & 106619 & 62716 \\
13 & 169063 & 108252 & 65634 \\
14 & 221506 & 157629 & 109776 \\
15 & 203497 & 135782 & 178407 \\
16 & 185584 & 155999 & 52203 \\
\hline Average & 140263.8 & 120433.1 & 66637.6 \\
Range & $1629-253514$ & $9119-340223$ & $4476-156822$ \\
\hline
\end{tabular}



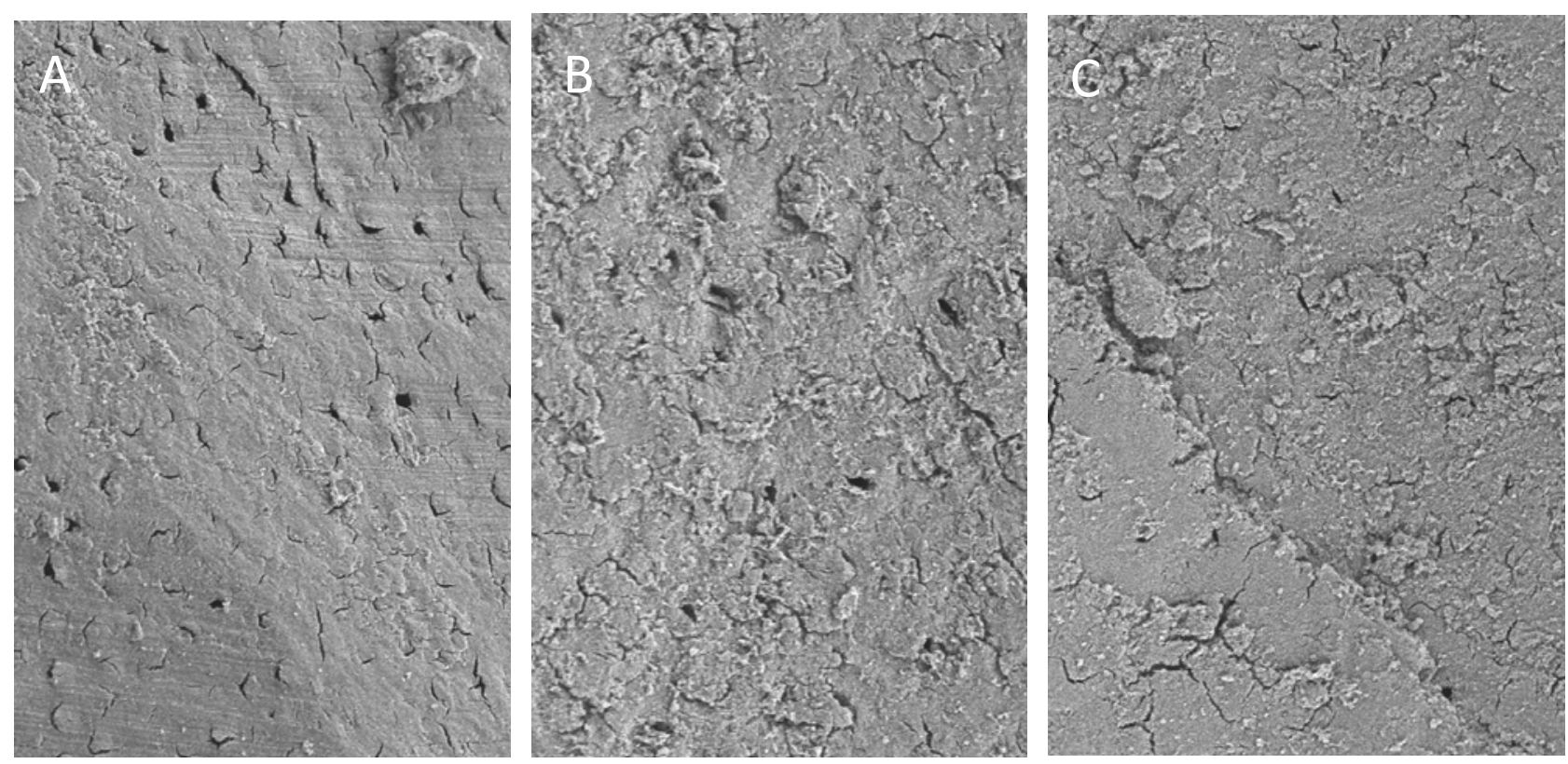

Figure 6. SEM Images of Tooth number 15 in the Control Group (magnification 1000x). (A) Coronal, (B) middle, (C) apex. This tooth was an average specimen from the control group and demonstrates the smear layer occluding most of the dentin tubules.
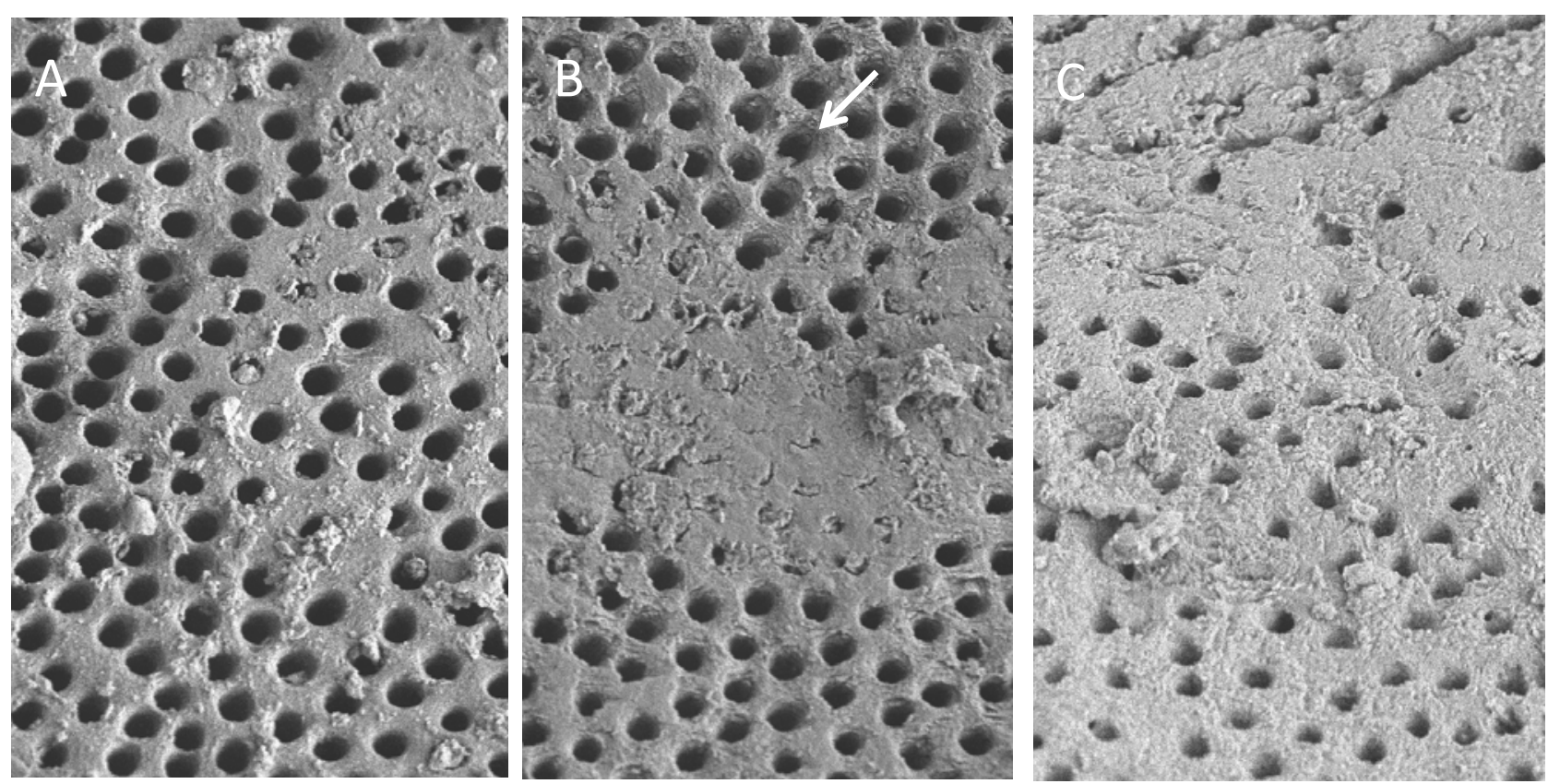

Figure 7. SEM Images of Tooth number 6 in the EDTA Group (magnification 1000x). (A) The coronal, (B) middle, (C) apex. This tooth was a good representative of the EDTA Group. Note the erosion of peritubular dentin indicated by the arrow. 

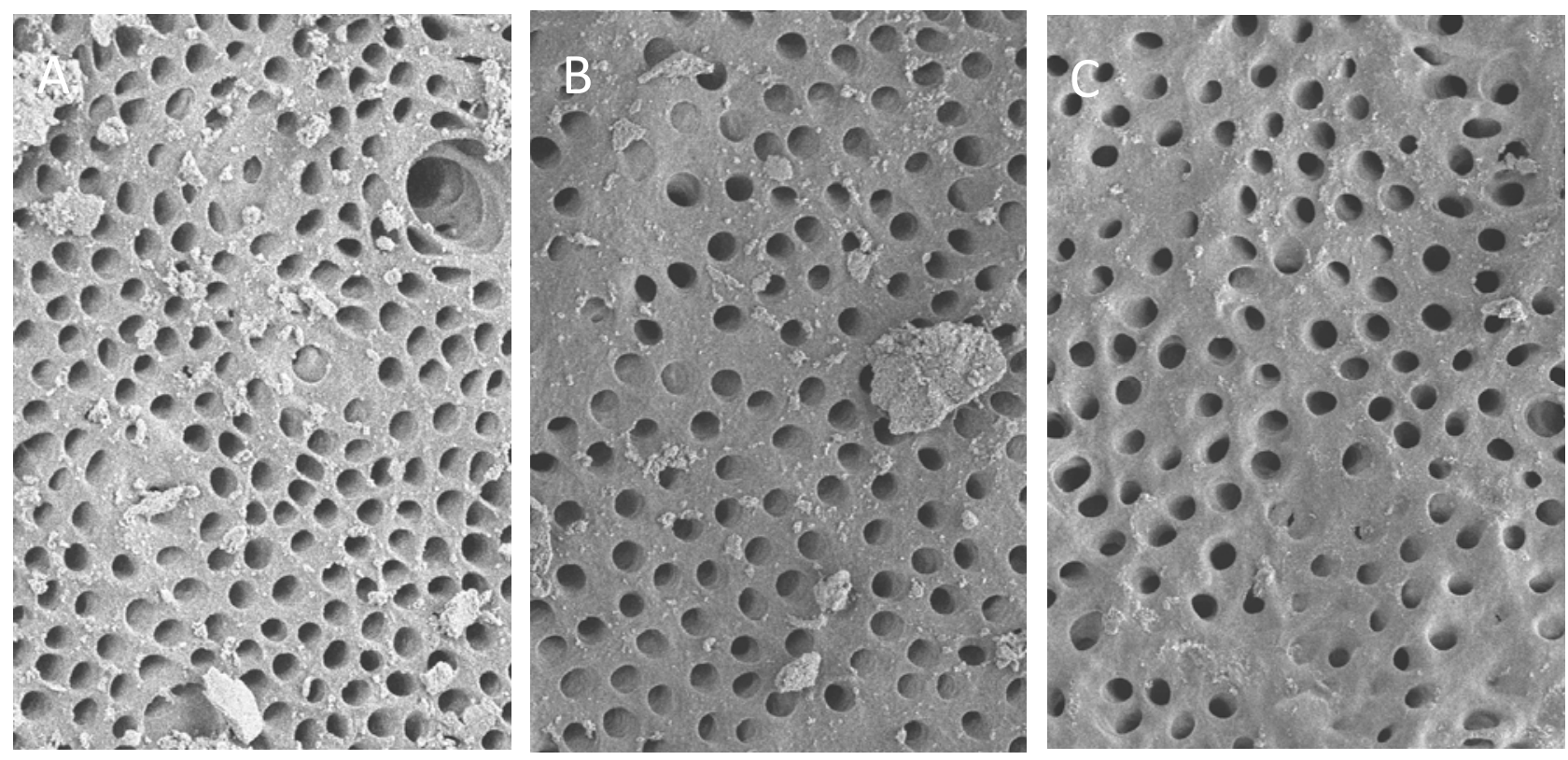

Figure 8. SEM Images of Tooth number 5 in the Maleic Acid Group (magnification 1000x). (A) The coronal, (B) middle, (C) apex. This tooth was representative of the MA group because it had no erosion and the majority of the tubules are free of debris.

Table 4. Effect Tests - This table, and the following three (5,6,7), display the least squares significance levels for the effects of group, canal location, and group/canal location.

\begin{tabular}{lccccc}
\hline Source & Nparm & DF & DFDen & F Ratio & Prob > F \\
\hline Irrigant & 2 & 2 & 44.92 & 23.8642 & $<.0001^{*}$ \\
Canal Location & 2 & 2 & 88.12 & 17.4634 & $<.0001^{*}$ \\
Irrigant*Canal & 4 & 4 & 88.11 & 4.2292 & $0.0035^{*}$ \\
Location & & & & & \\
\hline
\end{tabular}

Table 5. Group - Least Squares Means Table

\begin{tabular}{lcc}
\hline Level & Least Sq Mean & Std Error \\
\hline Control & 5591.44 & 10936.682 \\
EDTA & 74788.10 & 10457.302 \\
MA & 109111.46 & 10589.397 \\
\hline
\end{tabular}


Table 6. Canal Location - Least Squares Means

Table

\begin{tabular}{lcc}
\hline Level & Least Sq Mean & Std Error \\
\hline Apex & 34944.798 & 8117.0473 \\
Middle & 65461.656 & 8122.2076 \\
Crown & 89084.549 & 8122.2076 \\
\hline
\end{tabular}

Table 7. Irrigant*Canal Location - Least Squares Means

Table

\begin{tabular}{lcc}
\hline Level & Least Sq Mean & Std Error \\
\hline Control,Apex & 1006.93 & 14386.649 \\
Control,Middle & 9908.27 & 14386.649 \\
Control,Crown & 5859.13 & 14386.649 \\
EDTA,Apex & 37189.90 & 13855.063 \\
EDTA,Middle & 66043.64 & 13882.254 \\
EDTA,Crown & 121130.76 & 13882.254 \\
MA,Apex & 66637.56 & 13929.813 \\
MA,Middle & 120433.06 & 13929.813 \\
MA,Crown & 140263.75 & 13929.813 \\
\hline
\end{tabular}

Figure 9. Least Squares Means Plot - This graph visualizes (Table 7) the group over the canal location of each tooth. It also displays the profound difference between the control (A), EDTA (B), and maleic acid (C).

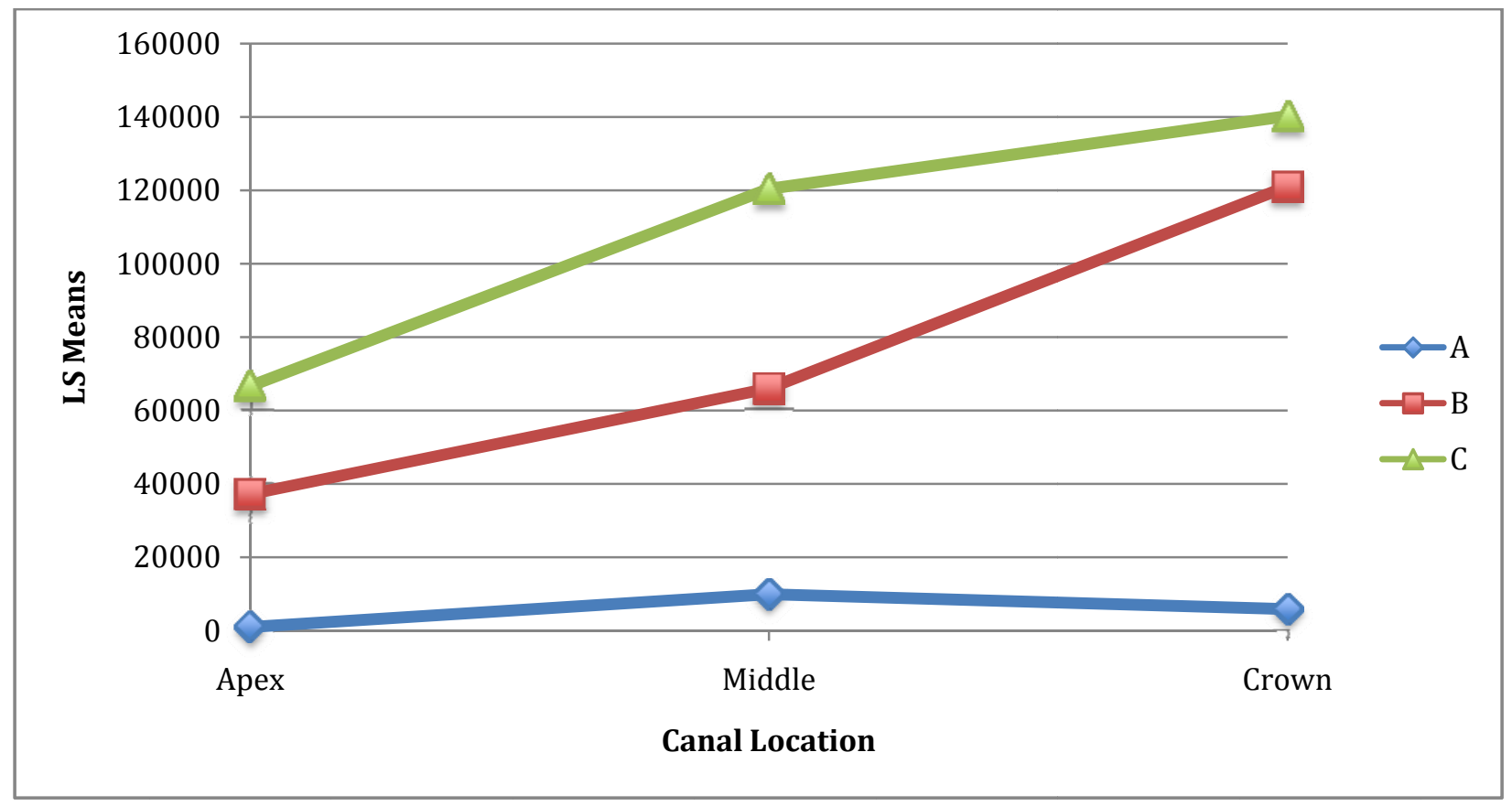




\section{DISCUSSION}

The purpose of this study was to determine if there was a difference between EDTA and MA in the removal of smear layer from curved root canals of human posterior teeth using a unique assay. Overall it was shown there was no statistical difference between EDTA and MA when comparing them in the coronal and apical locations of the canal. This contradicts the findings by Ballal and Prabhu $(7,33)$ that 7\% MA removed more smear layer than 17\% EDTA and was one reason for evaluating MA here.

All teeth selected had a root that curved at least 10 degrees and was from the posterior dentition. This is different from all other MA studies because they all used straight rooted anterior teeth. Using this type of teeth made the chemomechanical preparation more difficult and resulted in the loss of two teeth from the control group due to file separation. Most studies are done using straight rooted anterior teeth because they have a large canal and do not place added stress on the file. However, using straight rooted teeth does not demonstrate the true effectiveness of an irrigant because there is no curve that it must overcome. Unlike other MA research, this paper shows the type of tooth more commonly encountered by the everyday practitioner $(7,33)$.

The type of tooth utilized in this experiment also made the sectioning process much more difficult. Posterior roots tend to be slimmer than anterior roots and to add a curve to that equation made it extremely difficult to section them. It was shocking that only one tooth was lost during the process, which decreased the sample size of the MA group. However, this method was used because it was the same one utilized by several other studies and is the only current method available that will preserve the smear layer $(6,7,10,28,30,33)$. 
Analysis by the scanning electron microscope is required to visualize the smear layer. The images captured were similar to other studies. It was clear that EDTA caused peritubular dentin erosion while none was found with MA. Dentin erosion caused by EDTA has been demonstrated in other papers $(4,7)$. One problem with some of the SEM images was the contrast was too high or low. It would be better if the contrast could be standardized to aid in automated SEM image analysis.

This is the first study done with automated image analysis to analyze the smear layer, besides the original study completed by George that validated this process (10). It creates quantitative results instead of the usual subjective qualitative findings that previous studies used. Previous studies $(7,26,28)$ have used observers to assign a score to smear layer images and compare them. These studies produce qualitative results that introduce a large amount of observer error. In this paper the actual surface area (pixels ${ }^{2}$ ) of open tubules was calculated to give an accurate comparison between the groups. In order to use automated image analysis the image must be taken from a 90 degree angle. The more straight on the image is the more accurate the data will be because the computer can only use true black to calculate surface area. If the image is angled then the computer cannot detect the true tubule size due to distortion. This can introduce human error because it is a human that captures the image. In order to reduce human error the technician must be shown standardized images to know what must be captured in the image. Overall, this technique has much less subjectivity than using the observer ranking method.

Recent research has continued on MA and found that as low as a $0.88 \%$ MA solution was effective in eradicating E. faecalis in 30 seconds, while it took 15\% EDTA mixed with cetrimide one minute to eradicte it (34). This is important because $E$. faecalis is one of the most difficult 
bacteria to eradicate from a root canal system and is frequently found in failing root canal therapies. It has also been demonstrated that irrigating with MA for the final rinse decreased canal leakage and increased the push-out bond strength of AH plus when compared to EDTA (35). This demonstrates two more reasons that the endodontic community should consider switching from EDTA to MA.

The only requirement of an irrigant that MA does not fulfill is the ability to dissolve pulp tissue. It has been shown that $\mathrm{NaOCl}$ dissolves pulp tissue significantly better than $\mathrm{MA}$ and EDTA (36). Most likely this is due to the low $\mathrm{pH}$ of MA, which is around $\mathrm{pH} 1.05$ (36), because pulp dissolution occurs at a basic $\mathrm{pH}$. So it is still necessary to use $\mathrm{NaOCl}$ throughout the procedure, but a final rinse with MA would be beneficial.

Although there are still papers that disagree, the vast majority demonstrates that it is important to remove the smear layer (21). This author not only agrees that the smear layer should be removed, but also believes that it is time to replace EDTA with MA. The evidence that MA is better than EDTA continues to surface $(35,36)$. This paper found that MA performed significantly better in the middle portion and it was also shown that MA is consistent in smear layer removal. Overall, MA had a higher removal of smear layer, but it was only significant in the middle portion of the canal. If EDTA cannot be dependable when removing smear layer and it is shown that MA works every time, then that gives good reason to switch to MA. At this time MA is not readily available on the market for dentist to purchase but compounding pharmacies can make it. Because it must be compounded, MA is a more expensive material than EDTA. Currently an 8 ounce bottle of EDTA costs $\$ 29.99$ and a 12 bottle of compounded MA costs $\$ 95$; which translates to $\$ 4$ an oz for EDTA and $\$ 8$ an oz for MA. In my practice I will use a compounded MA for the multiple reasons stated previously in this paper that demonstrate its 
superiority to EDTA. More research is needed to bring a paradigm shift to the dental companies to mass-produce this product. EDTA is the current product on the market because, until now, there has been nothing better. Future studies need to be done to determine the shelf-life of MA, its ease of use, and its substantivity.

This paper is important because it is the first time automated image analysis has been used to compare irrigants in smear layer removal. This method needs to become the gold standard for analysis because it is more standardized and analytical, which eliminates the subjective score. A true quantitative analysis can be preformed making the data stronger. Although the software is expensive, this it the future of smear layer analysis and it should be utilized.

This manuscript was arranged with the intent of publishing our findings; hence given the journal limitations of figures/tables, only selected images were highlighted. 


\section{CHAPTER V}

\section{SUMMARY}

It was hypothesized that there would be no difference between EDTA and MA in removal of smear layer from the canals. However, it was discovered that MA was significantly better than EDTA at smear layer removal in the middle portion of the canal and the null hypothesis was rejected. There was no difference between EDTA and MA in the coronal and apical locations of the canal. It was also observed that EDTA caused peritubular dentin erosion while MA showed no signs of erosion. It is possible that canal shape and size affected the outcome of this study.

MA is the better final irrigant because it does not cause erosion, consistently removes the smear layer, and is less cytotoxic than EDTA. It is also more effective at eradicating E. faecalis and creates a stronger bond strength with AH plus. The negative of MA is that it is not readily available at this time from dental suppliers.

It is important for more research to be done to demonstrate the effectiveness of MA. More studies should be done on teeth with curved canals to demonstrate how effective MA is in the apical third. The most important result of this study is the strength of the data from automated image analysis. This paper has demonstrated that a true comparison can and should be made using this method.

\section{CONCLUSION}

MA removed a significantly greater surface area of smear layer in the middle portion of the canal than EDTA, but was similar in the coronal and apical locations. MA was the only irrigant to consistently remove smear layer in every tooth at every canal location. It was also observed 
that EDTA caused peritubular dentin erosion. This method provides higher resolution in comparative analysis and points out variability in tooth selection. 


\section{Acknowledgements}

I would like to thank Adrienne McGrew (WVU School of Engineering) for running the scanning electron microscope and capturing the images and Dr. Richard Turton (Professor chemical engineering, WVU) for help with the Visilog software. 


\section{REFERENCES}

1. Violich DR, Chandler NP. The smear layer in endodontics- a review. Int Endod J 2010; 43:2-15.

2. Pashley DH. Smear layer: physciological considerations. Oper Dent 1983; Supp 3:13-29.

3. Hulsmann M, Heckendorff M, Lennon A. Chelating affents in root canal treatement: mode of action and indications for their use. Int Endod J 2003; 36:810-830.

4. Calt S, Serper A. Time-dependent effects of EDTA on dentin structures. J of Endod 2002; 28:17-19.

5. Sen BH, Erturk O, Piskin B. The effect of different concentrations of EDTA on instrumented root canal walls. Oral Surg Oral Med Oral Pathol Oral Radiol Endod 2009; 108:622-627.

6. Baumgartner JC, Mader CL. A scanning electron microscopic evaluation of four root canal irrigation regimens. J Endod 1987; 13:147-157.

7. Ballal NV, Kanadian S, Mala K, Bhat KS, Acharya S. Comparison of the efficacy of maleic acid and ethylenediaminetetraacetic acid in smear layer removal from instrumented human root canal: a scanning electron microscopic study. J Endod 2009; 35:1573-1576.

8. Ballal NV, Kundabala M, Bhat S, Rao N, Rao BSS. A comparative in vitro evaluation of cytotoxic effects of EDTA and maleic acid: root canal irrigants. Oral Surg Oral Med Oral Pathol Oral Radiol Endod 2009; 108:633-638.

9. Ballal NV, Kundabala M, Bhat KS. A comparative evaluation of postobturation apical seal following intracanal irrigation with maleic acid and EDTA: a dye leakage under vacuum study. Oral Surg Oral Med Oral Pathol Oral Radiol Endod 2010; 109:e126-e130.

10. George R, Rutley EB, Walsh L. Evaluation of smear layer: a comparison of automated image analysis versus expert observers. J Endod 2008; 34:999-1002. 
11. Ciocca L, Gallina I, Navacchia E, Baldissara P, Scotti R. A new method for quantitative analysis of dentinal tubules. Comput Biol Med 2007; 37:277-286.

12. Saunders WP, Saunders EM. Influence of smear layer on the coronal leakage of Thermafil and laterally condensed gutta-percha root fillings with a glass ionomer sealer. J Endod 1994; 20:155-158.

13. Taylor JK, Jeansonne BG, Lemon RR. Coronal leakage: effects of smear layer, obturation technique, and sealer. J Endod 1997; 23:508-512.

14. Froes, JA, Horta HG, DaSilveira AB. Smear layer influence on the apical seal of four different obturation techniques. J Endod 2000;26:351-4.

15. Timpawat S, Vongsavan N, Messer HH. Effect of removal of the smear layer on apical microleakage. J Endod 2001;27:351-3.

16. Timpawat S, Sripanaratanakul S. Apical sealing ability of glass ionomer sealer with and without smear layer. J Endod 1998;24:343-5.

17. Kennedy WA, Walker WA, Gough RW. Smear layer removal effects on apical leakage. J Endod 1986;12:21-7.

18. Cobankara FK, Adanir N, Belli S. Evaluation of the influence of smear layer on the apical and coronal sealing ability of two sealers. J Endod 2004;30:406-9.

19. Economides N, Liolios E, Kolokuris I, Beltes P. Long-term evaluation of the influence of smear layer removal on the sealing ability of different sealers. J Endod 1999;25:123-5.

20. Tzanetakis GN, Kakavetsos VD, Kontakiotis EG. Impact of smear layer on sealing property of root canal obturation using 3 different techniques and sealers. Part I. Oral surg oral med oral pathol oral radiol endod 2010;109:145-52. 
21. Shahravan A, Haghdoost AA, Adl A, Rahimi H, Shadifar F. Effect of smear layer on sealing ability of canal obturation: a systematic review and meta-analysis. J Endod 2007;33:96-105.

22. Clark-Holke D, Drake D, Walton R, Rivera E, Guthmiller JM. Bacterial penetration through canals of endodontically treated teeth in the presence or absence of the smear layer. $\mathrm{J}$ Dentistry 2003;31:275-81.

23. Saleh M, ryter IE, Haapasalo M, Orstavik D. Bacterial penetration along different root canal filling materials in the presence or absence of smear layer. Int Endod J 2008;41:32-40.

24. Kokkas AB, Boutsioukis AC, Vassiliadis LP, Stavrianos CK. The influence of the smear layer on dentinal tubule penetration depth by three different root canal sealers: an in vitro study. J Endod 2004;30:100-2.

25. Khademi a, Yazdizadeh M, Feizianfard M. Determination of the minimum instrumentation size for penetration of irrigants to the apical third root canal systems. J Endod 2006;32:417420.

26. Zehnder M. Root Canal Irrigants. J Endod 2006;32:389-98.

27. Zehnder M, Schmidlin P, Sener B, Waltimo T. Chelation in root canal therapy reconsidered. J Endod 2005;31:817-20.

28. Mancini M, Armellin E, Casaglia A, Cerroni L, Cianconi L. A comparative study of smear layer removal and erosion in apical intraradicular dentine with three irrigating solutions: a scanning electron microscopy evaluation. J Endod 2009;35:900-3.

29. Teixeira CS, Felippe MC, Felippe WT. The effect of application time of edta and naocl on intracanal smear layer removal: an sem analysis. Int Endod J 2005;38:285-90.

30. Niu W, Yoshioka T, Suda H. A scanning electron microscoping study of dentinal erosion by final irrigation with edta and naocl solutions. Int Endod J 2002;35:934-9. 
31. Bramant CM, Betti LV. Comparative analysis of curved root canal preparation using nickeltitanium instruments with or without edta. J Endod 2000;26:278-80.

32. Breschi L, Gobbi P, Mazzotti G, Falconi M, Ellis TH, Stangel I. High resolution sem evaluation of dentin etched with maleic and citric acid. Dental Materials 2002;18:26-35.

33. Prabhu SG, Rahim N, Bhat KS, Mathew J. Comparison of removal of endodontic smear layer using naocl, edta, and different concentrations of maleic acid - a sem study. Endodontology 2003;15:20-5.

34. Ferrer-Luque CM, Arias-Moliz MT, Gonzalez-Rodriguez MP, Baca P. Antimicrobial activity of maleic acid and combinations of cetrimide with chelating agents against Enterococcus faecalis biofilm. J Endod 2010;36:1673-75.

35. Neelakantan P, Subbarao C, Subbarao CV, De-Deus G, Zehnder M. The impact of root dentine conditioning on sealing ability and push-out bond strength of an epoxy resin root canal sealer. Int Endod J 2011;44:491-8.

36. Ballal NV, Mala K, Bhat KS. Effect of maleic acid and ethylenediaminetetraacetic acid on the dissolution of human pulp tissue- an in vitro study. Int Endod J 2011;44:353-6. 
Appendix A: Scanning Electron Microscope Protocol and Information

Samples are placed face-up on two-sided carbon tape adhered to an aluminum sample stub.

The samples are then placed in the evacuation/coating chamber of an SPI-module Sputter coater and the chamber is evacuated to less than 4 millitorr. Once this level of vacuum is achieved, the chamber is briefly flushed with argon and restored to a vacuum of less than 2 millitorr.

The argon flow is then restarted and adjusted until the test value of the plasma current is set at 18 milliamps. The timer is then checked to verify seconds of coating time, which under ideal conditions will deposit approximately angstroms of gold-palladium onto the sample, and the timer is started.

Once the timer has reached zero the plasma discharge is stopped, and the pumps and the Sputter unit are switched off. The evacuation/coating chamber is then returned to atmospheric pressure, and the sample is removed.

Once coated, the sample stub is mounted to the appropriate holder and placed in the Sample Exchange Chamber (SEC) of the SEM (see specifications below for model details). Once vacuum in the SEC is below $4 \times 10^{-3} \mathrm{~Pa}$, the sample assembly is transferred into the Sample Chamber and the High Voltage is applied to the SEM tip. Samples in this series were examined using a $5 \mathrm{kVolt}$ beam, at a working distance of approximately $12 \mathrm{~mm}$, using the lower detector.

Hitachi S-4700 Field Emission Scanning Electron Microscope

Manufacturer: Hitachi

Model: S-4700

Type: Cold Field Emission

Technical characteristics:

- accelerating voltage: $0.5-30 \mathrm{kV}$

- magnification: X30 - X500,000

- high resolution at low accelerating voltage;

- automatic image processing and data recording

- chemical analysis through an EDS (Energy Dispersive Spectrometer) system

The Hitachi S-4700 SEM operates using a cold field emission electron source. A single crystal tungsten tip with a $100 \mathrm{~nm}$ curvature radius acts as a cathode. Together with two sets of anodes and in a high vacuum environment (as low as $1 \times 10-8 \mathrm{~Pa}$ at the last ion pump), it is able to generate an electron beam with a virtual source size as small as 3nm in diameter. The S-4700 combines secondary (SE) and backscattered (BSE) electron detection in a single unit, as well as input from upper and lower detectors.

Elemental analysis (including "light elements" from Boron up) is possible using the energy dispersive spectrometer. 
Appendix B: Scanning Electron Microscope Images

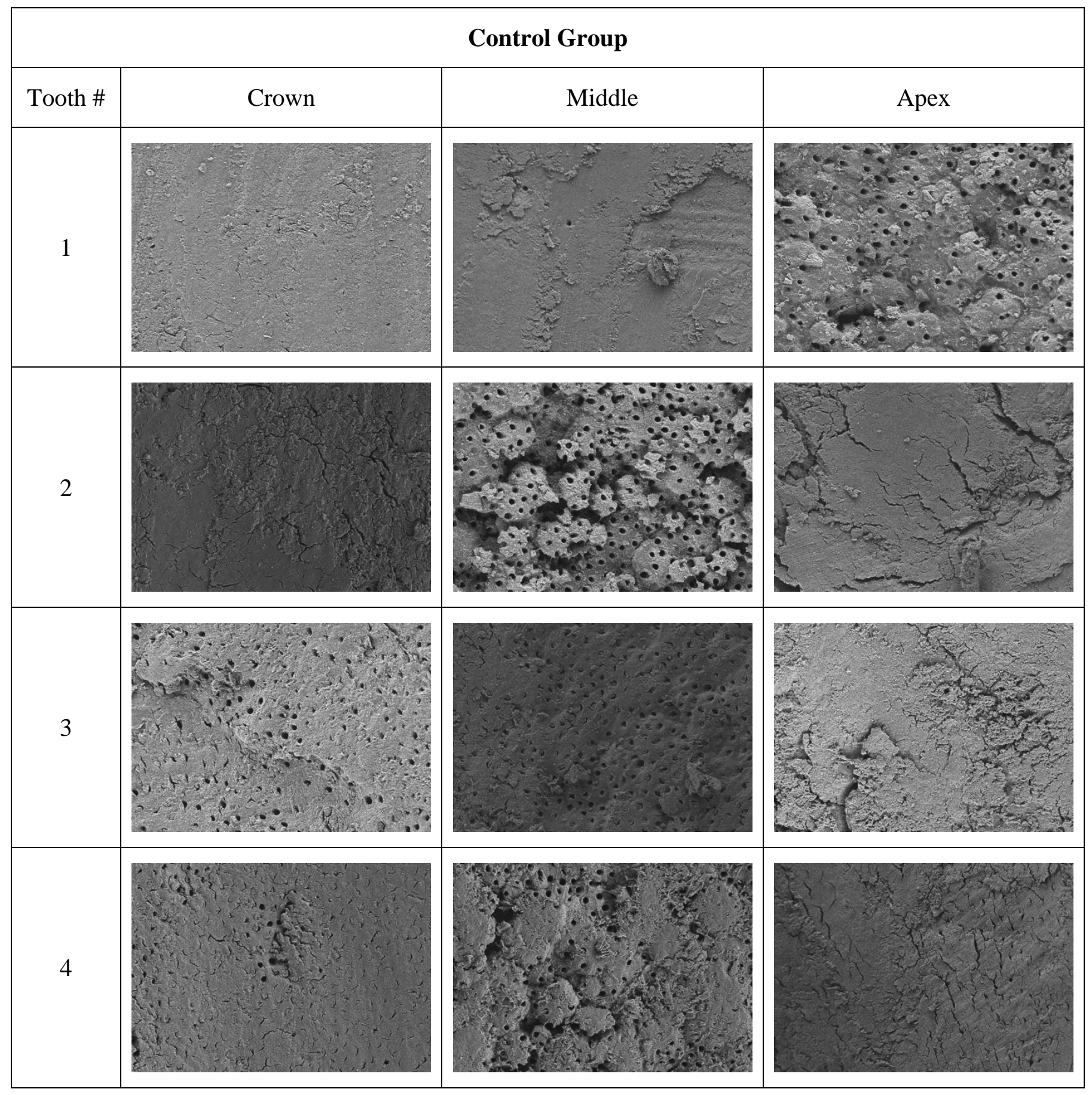




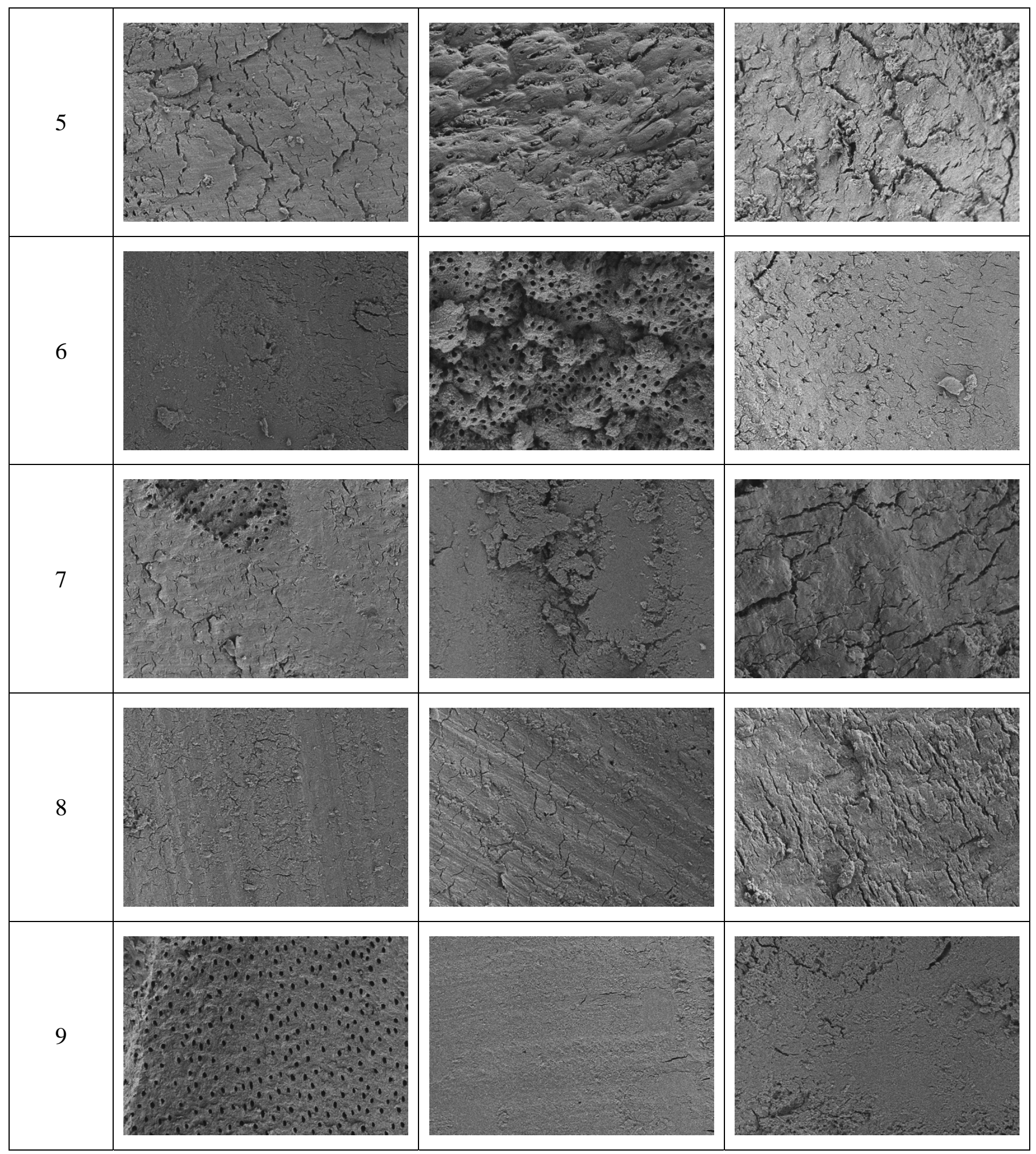




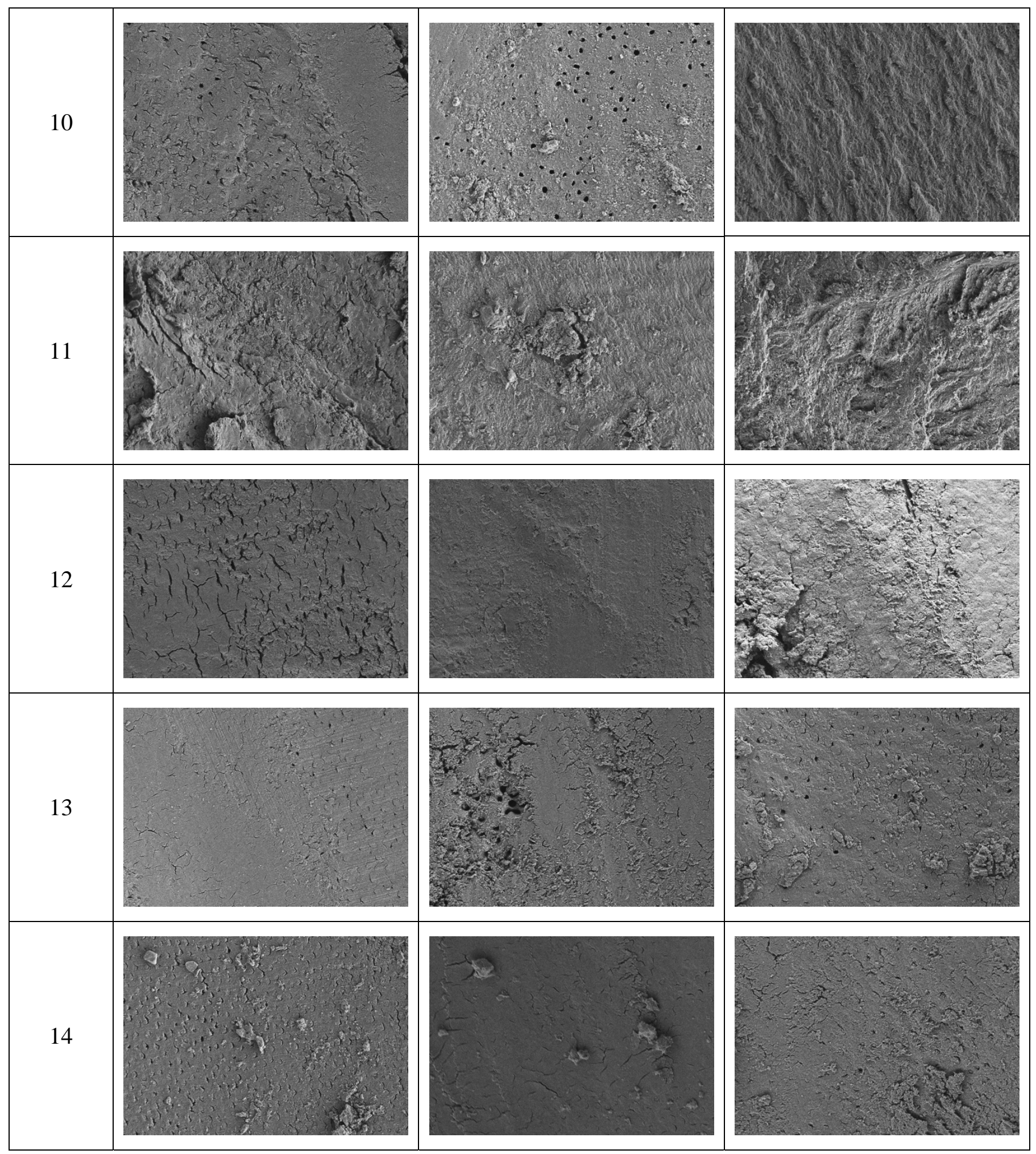




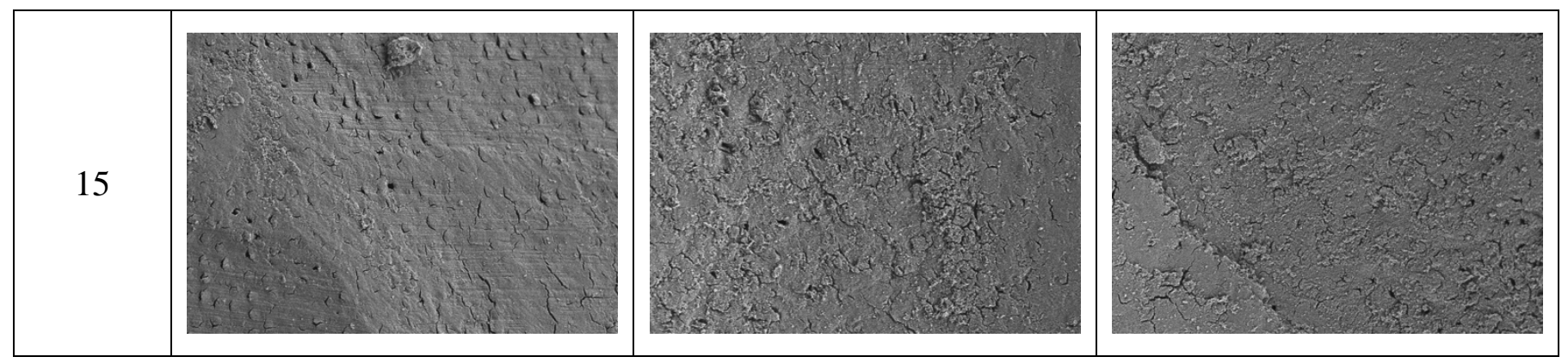

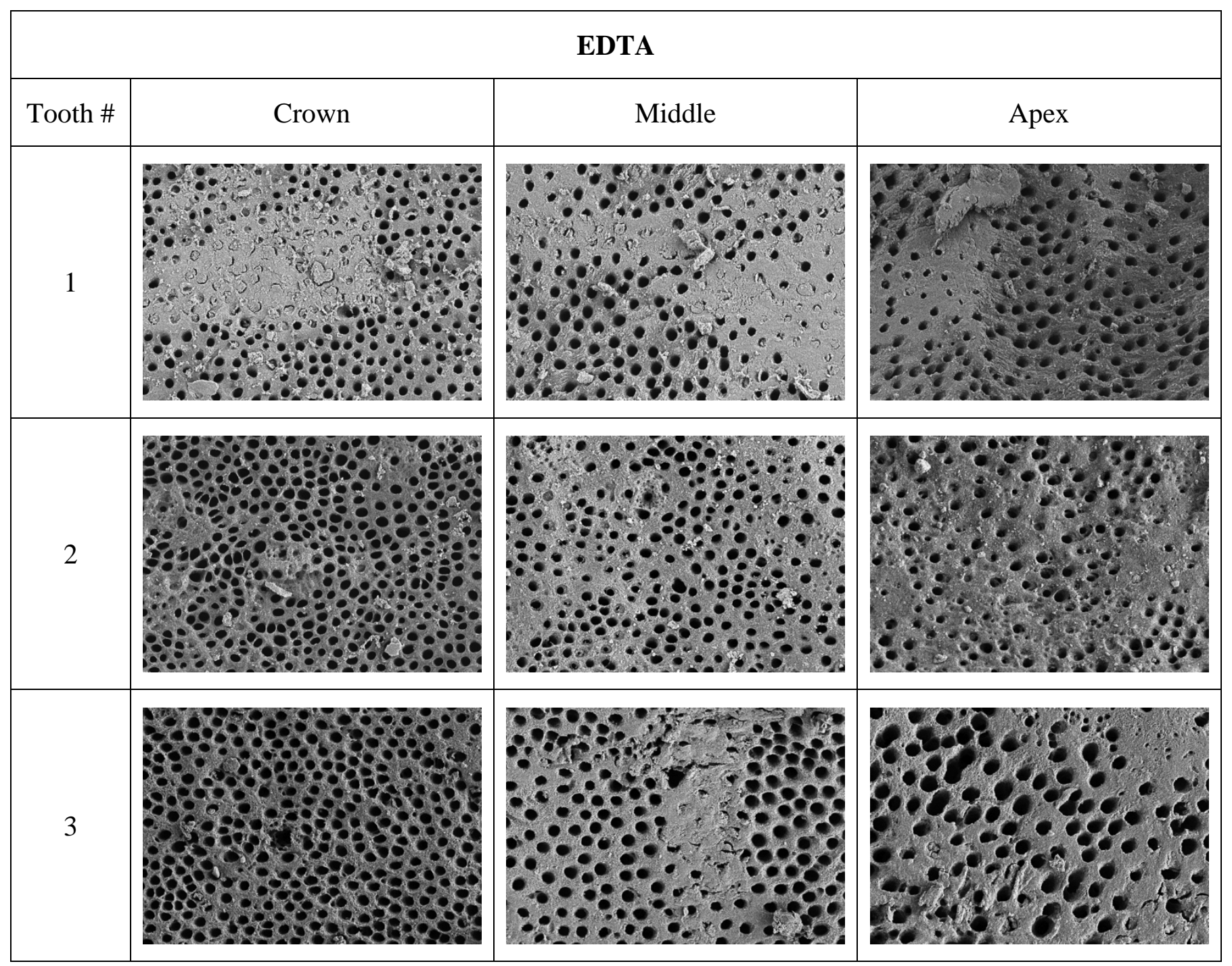




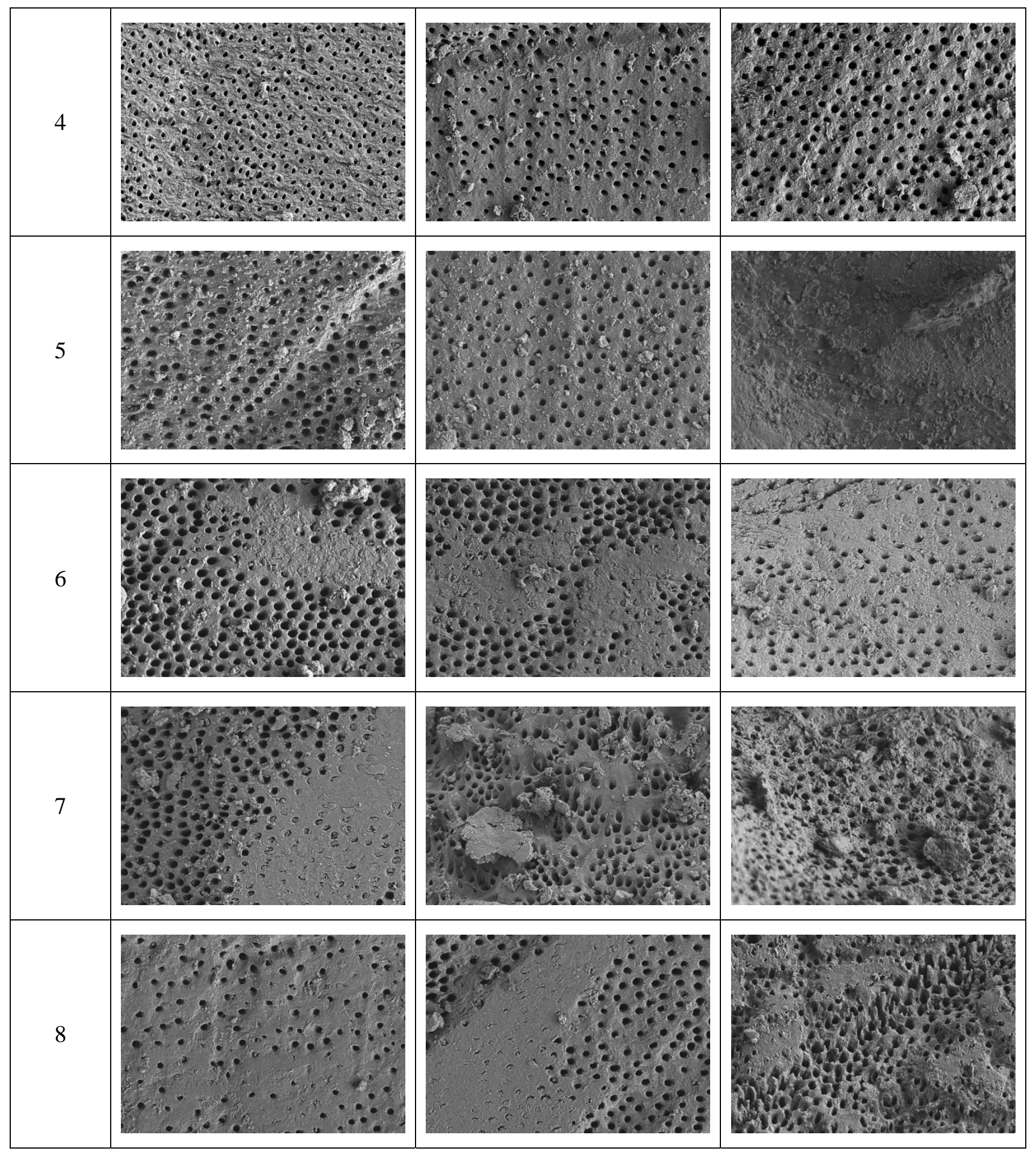




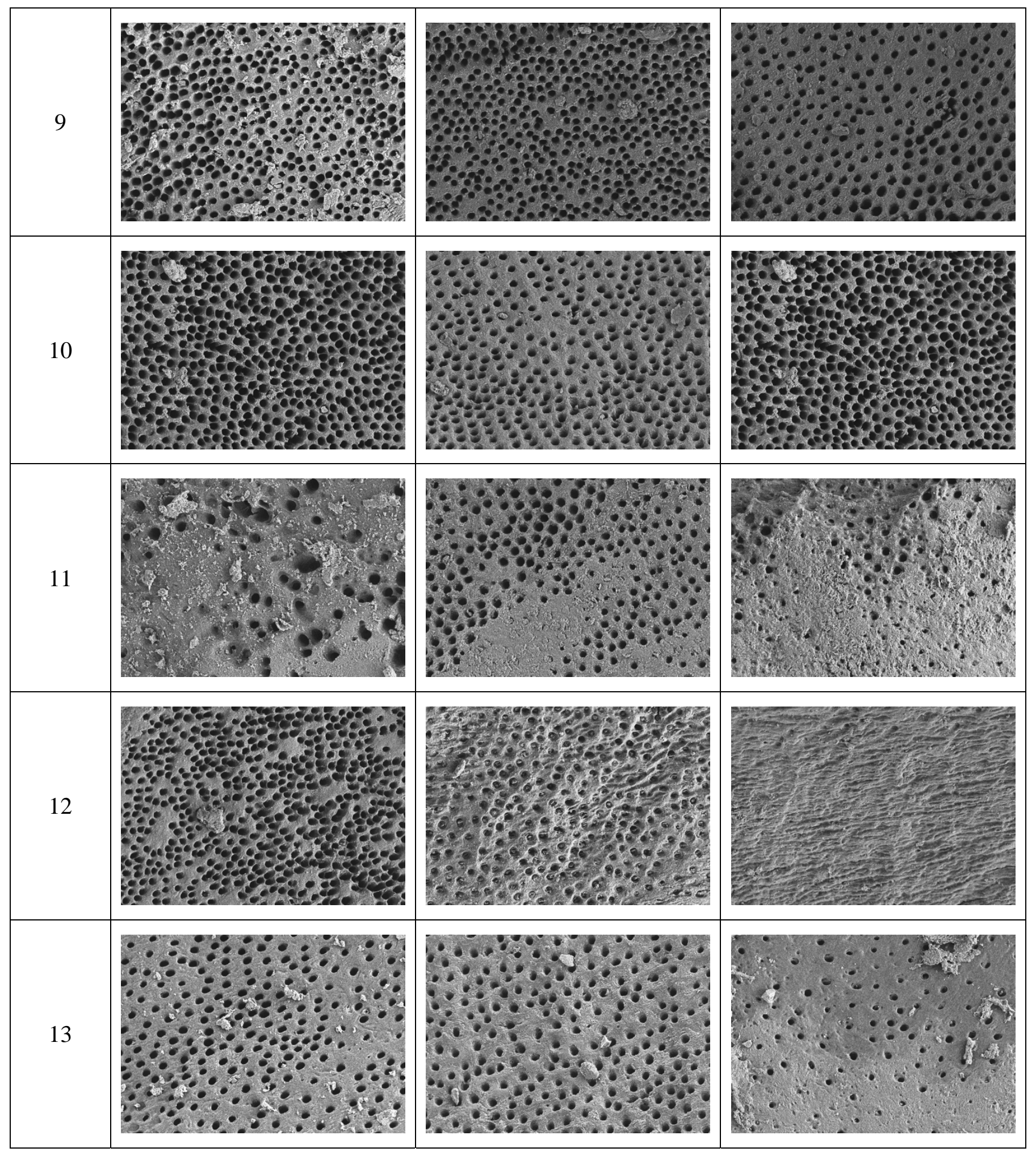




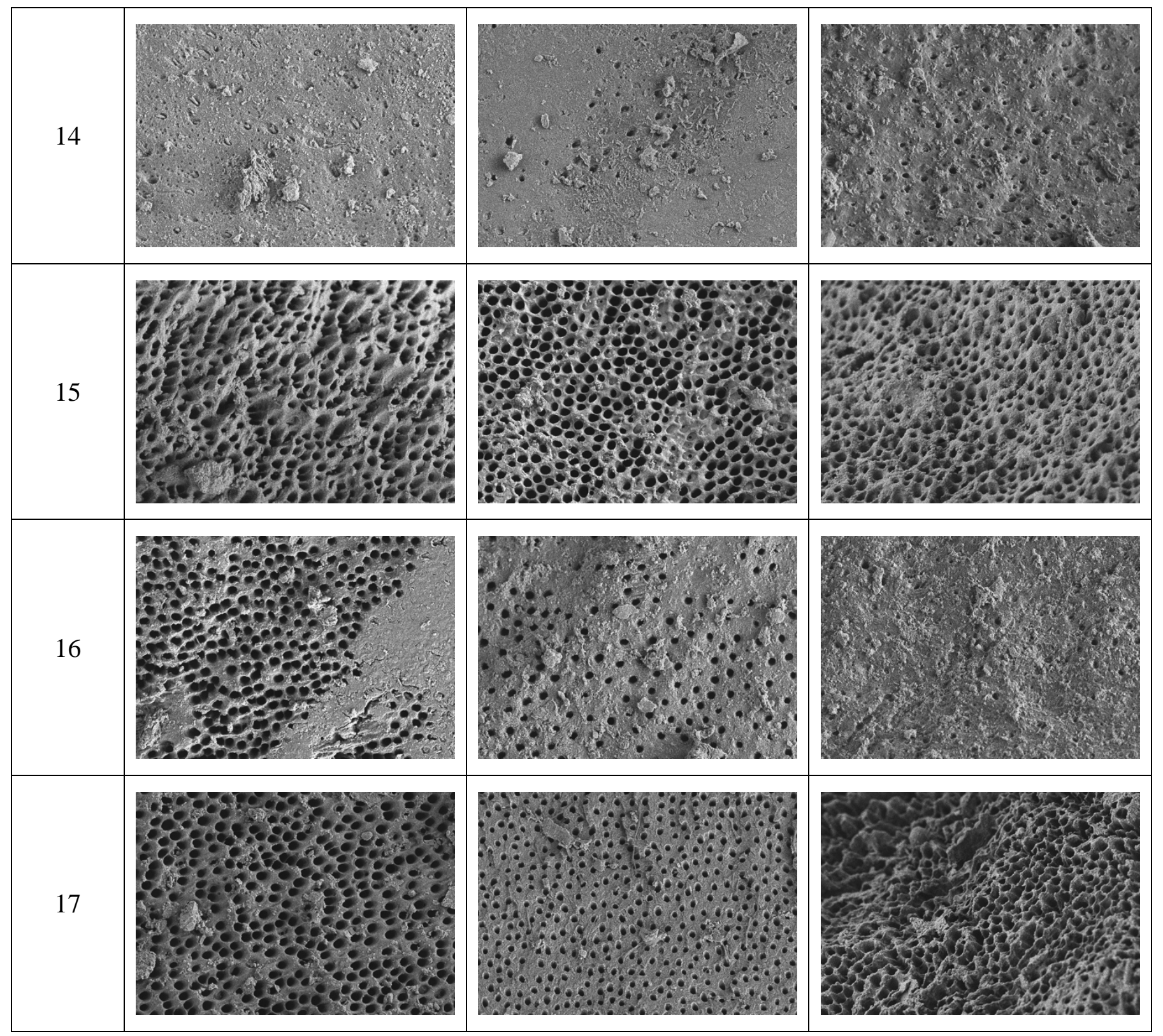




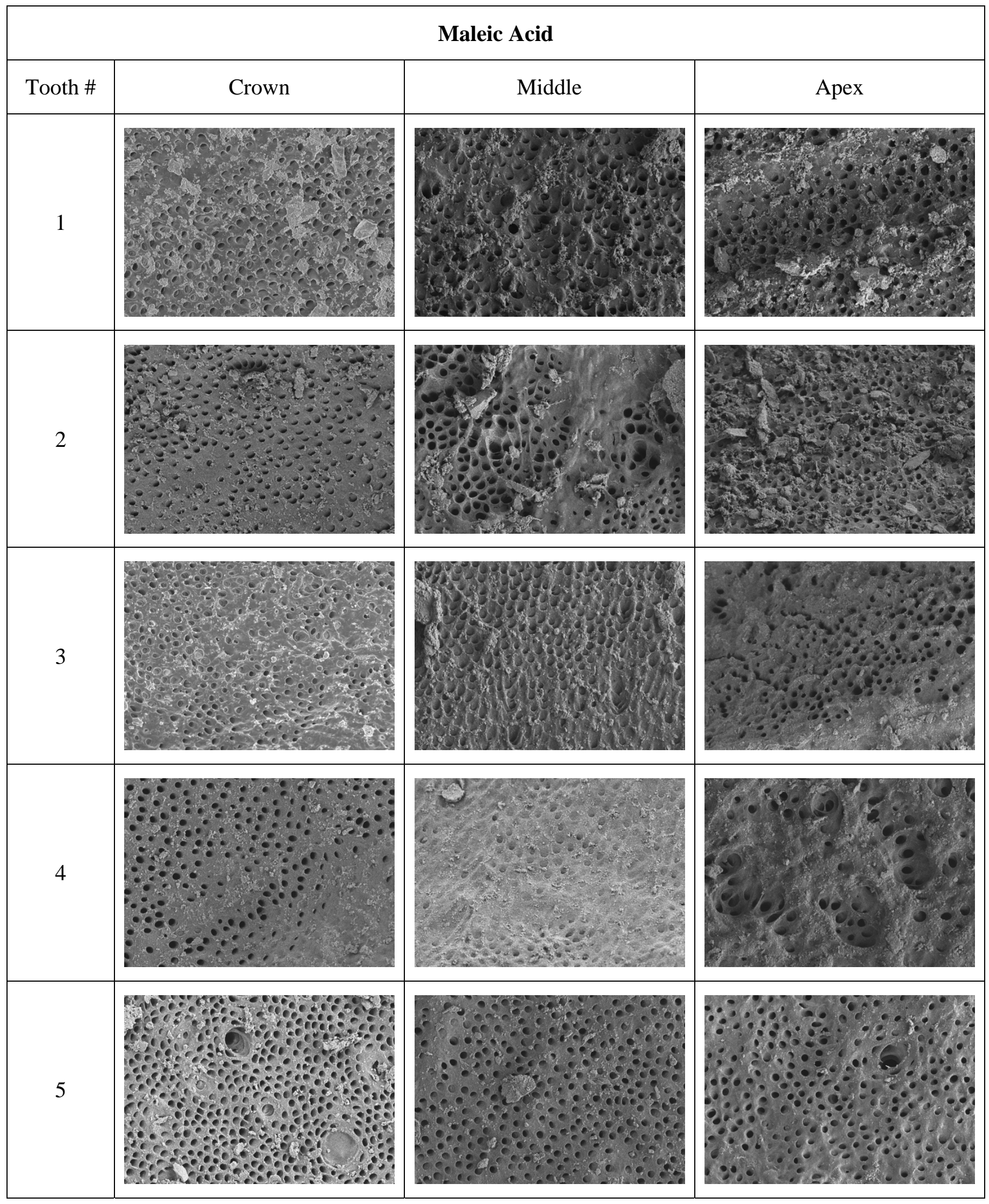




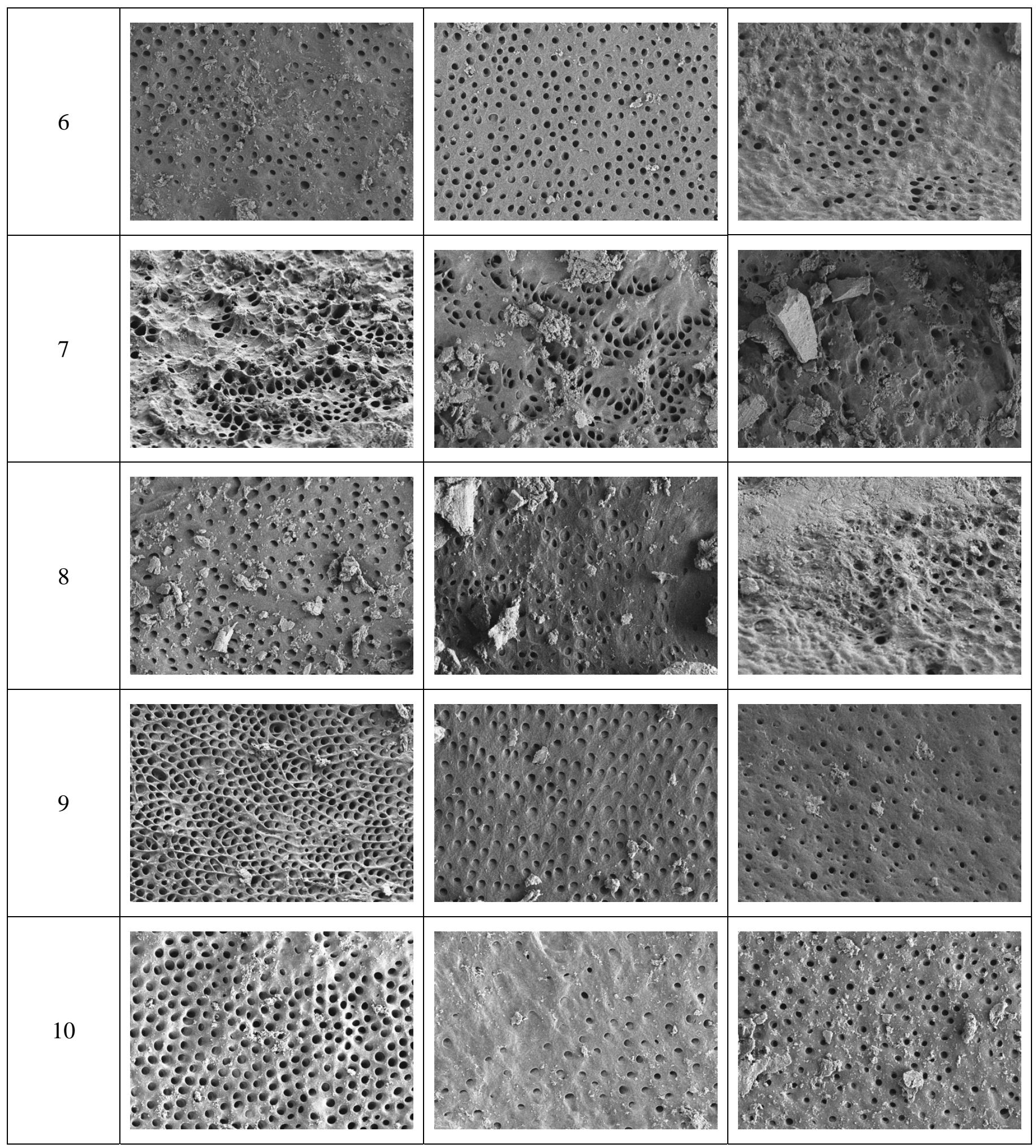




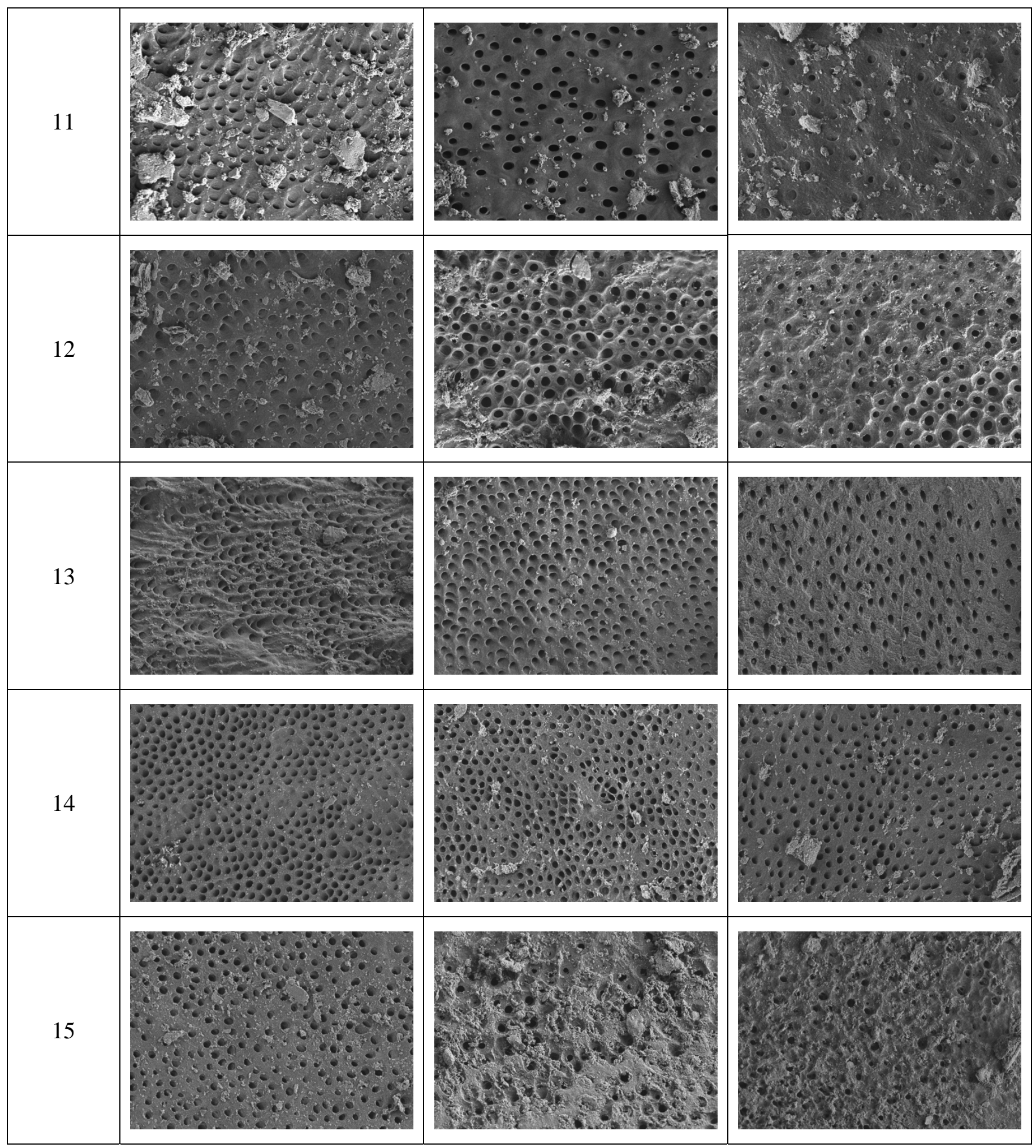




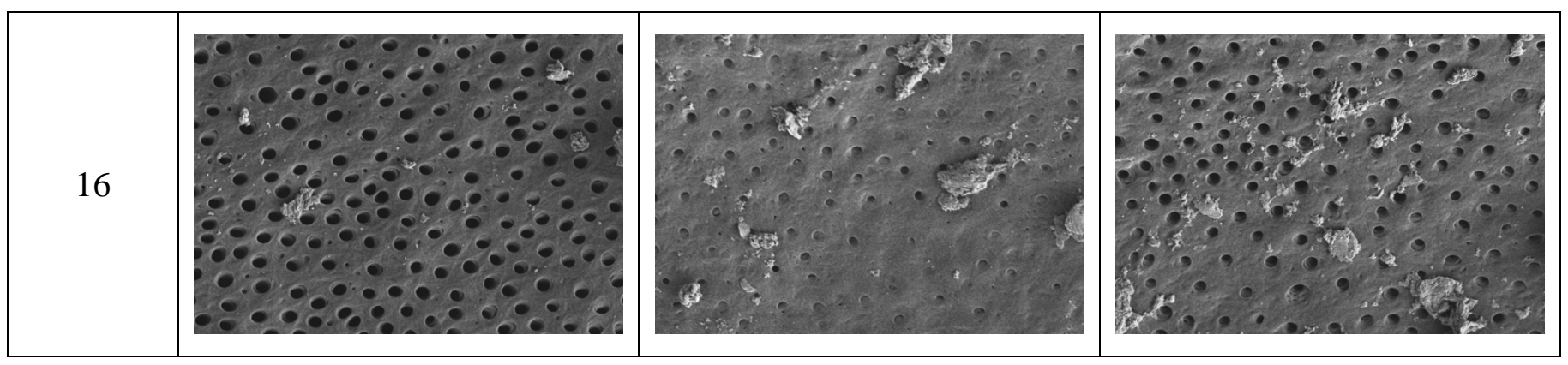

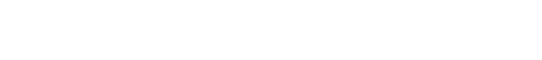

VN: $\mathrm{cn}=$ John H. Hagen, o=West

ou=Acquisitions Department,

H2019 $\begin{aligned} & \text { email=John. Hagen@mail.wvu.ed } \\ & \begin{array}{l}u, c=U S \\ \text { Date: 2011.07.25 10:47:33-04'00' }\end{array}\end{aligned}$ 